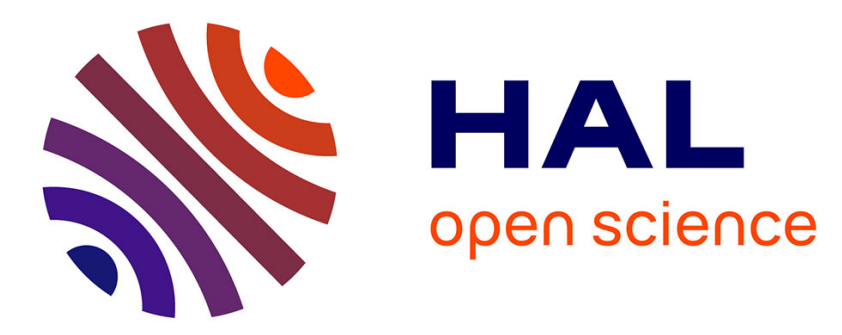

\title{
Multi-scale investigation of highly anisotropic zinc alloys using crystal plasticity and inverse analysis
}

\author{
Ludovic Cauvin, Balaji Raghavan, Salima Bouvier, Xiaodong Wang, Fodil \\ Meraghni
}

\section{- To cite this version:}

Ludovic Cauvin, Balaji Raghavan, Salima Bouvier, Xiaodong Wang, Fodil Meraghni. Multi-scale investigation of highly anisotropic zinc alloys using crystal plasticity and inverse analysis. Materials Science and Engineering: A, 2018, 729, pp.106-118. 10.1016/j.msea.2018.05.038 . hal-01797288

\section{HAL Id: hal-01797288 \\ https://hal.science/hal-01797288}

Submitted on 22 May 2018

HAL is a multi-disciplinary open access archive for the deposit and dissemination of scientific research documents, whether they are published or not. The documents may come from teaching and research institutions in France or abroad, or from public or private research centers.
L'archive ouverte pluridisciplinaire HAL, est destinée au dépôt et à la diffusion de documents scientifiques de niveau recherche, publiés ou non, émanant des établissements d'enseignement et de recherche français ou étrangers, des laboratoires publics ou privés. 


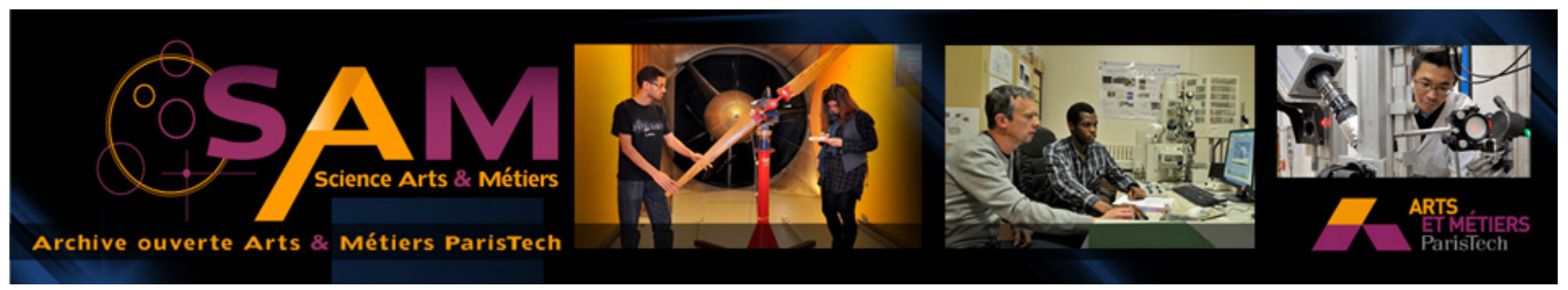

Science Arts \& Métiers (SAM)

is an open access repository that collects the work of Arts et Métiers ParisTech researchers and makes it freely available over the web where possible.

This is an author-deposited version published in: http://sam.ensam.eu

Handle ID: .http://hdl.handle.net/null

\section{To cite this version :}

Ludovic CAUVIN, Balaji RAGHAVAN, Salima BOUVIER, Xiaodong WANG, Fodil MERAGHNI Multi-scale investigation of highly anisotropic zinc alloys using crystal plasticity and inverse analysis - Materials Science \& Engineering A - Vol. 729, p.106-118 - 2018 


\title{
Multi-scale investigation of highly anisotropic zinc alloys using crystal plasticity and inverse analysis
}

\author{
Ludovic Cauvin $^{\mathrm{a}, *}$, Balaji Raghavan ${ }^{\mathrm{b}}$, Salima Bouvier ${ }^{\mathrm{a}}$, Xiaodong Wang ${ }^{\mathrm{a}}$, Fodil Meraghni ${ }^{\mathrm{c}}$ \\ a Sorbonne Universités, Université de Technologie de Compiègne, FRE UTC-CNRS 2012, Compiègne, France \\ b Laboratoire de Génie Civil et Génie Mécanique EA 3913, INSA de Rennes, France \\ ${ }^{\mathrm{c}}$ Arts et Métiers ParisTech Metz, LEM3 UMR CNRS 7239, Metz, France
}

\begin{abstract}
A B S T R A C T
Zinc and its alloys are important industrial materials due to their high corrosion resistance, low cost and good ductility. However, the characterization of these materials remains a difficult task due to their highly anisotropic behavior, the latter being due to the influence of microstructural effects, i.e. loading orientation-dependent activation of different families of slip systems and subsequent texture evolution, rendering the development of a reliable material model considerably difficult. A micro-mechanical approach based on polycrystal plasticity would better describe the physical mechanisms underlying the macroscopic behavior. This improved model should ostensibly improve the comprehension of the mechanical behavior, compared to the macroscopic approach using solely phenomenological anisotropy models along with a prohibitively large number of experiments required to identify the material parameters. In this paper, a multi-scale Visco-Plastic Self-Consistent (VPSC) approach is used. It is based on a micro-scale model calibrated by microstructural and deformation mechanism information based on Electron Back-Scattered Diffraction (EBSD) to describe the macroscopic anisotropic mechanical response during sheet metal deformation. The critical resolved shear stress (CRSS) as well as the micro-scale crystal parameters are obtained by an inverse analysis comparing the simulated and experimental results in terms of obtained tensile curves along three different directions. In order to obtain a global solution for the identification, we then use the Covariance Matrix Adaptation-Evolution Strategy (CMA-ES) genetic algorithm to the inverse problem. We validate our approach by comparing the simulated and experimental textures and activated slip systems. Finally, the identified mechanical parameters are used to investigate the anisotropy of the alloy and predict its formability by determining the corresponding R-values and Hill yield coefficients.
\end{abstract}

\section{Introduction}

Zinc and zinc-based alloys are valuable engineering materials whose industrial consumption ranks a close third behind those of $\mathrm{Al}$ and $\mathrm{Cu}$ among non-ferrous metals. Rolled sheets made from zinc alloys present a plethora of advantages including good aesthetic quality i.e. excellent visual appearance, long life with minimal maintenance needed, reduced cost, high adaptability and high creep resistance (for $\mathrm{Zn}-\mathrm{Cu}$-Ti alloys in particular), all of which enable their widespread use in construction for the fabrication of roofing products, cladding, flashings, rainwater down-pipes disposal applications, as well as in more innovative architectural designs $[1]$.

The main defects of deformed parts during sheet metal forming processes on zinc alloys include: crack, wrinkle, springback and surface deflections. Appropriate mechanical models and simulation tools capable of predicting the formability of rolled $\mathrm{Zn}$ sheets are needed to realize their full potential as engineering materials. Mechanical characterization typically involves the use of a variety of mechanical tests such as uniaxial and biaxial tensile tests (for ductile materials such as metals and alloys), different compression tests (for brittle and quasibrittle materials such as concrete) and relatively recent quasi-nondestructive tests such as instrumented indentation [2,3], with the ultimate aim of determining its macroscopic mechanical plastic behavior: (e.g. yield surface, strain hardening, Lankford coefficients). Numerical simulation is widely adopted to complement, and in some cases replace, experimental tests and error methods in order to reduce the time and cost of development.

For several decades, material behavior has been described using phenomenological constitutive relations in the general framework of the theory of elasto-visco-plasticity. This approach, albeit useful for 
simulating boundary value problems in a realistic manner with the help of finite element methods, has potential limitations for very anisotropic materials. These could be improved upon by taking into account the fundamental mechanisms involved during mechanical deformation.

Much of the literature on characterizing rolled sheets of Zn-based alloys is related to studying their corrosion resistance [4,5] since these materials are frequently used in chemically aggressive environments. However, in most of these studies, the evolution of mechanical behavior has rarely been examined, with the exception of analyzing the hardness evolution [6].

Zinc is in fact a highly anisotropic material that is very difficult to properly characterize due to the effect of its microstructure and initial crystallographic texture. At the micro-scale level, metal plasticity involves the nucleation and migration of dislocations in the crystals and polycrystals as the underlying basis for microstructure evolution during plastic flow. As the individual crystals have different sizes and orientations, i.e., the crystallographic texture, the anisotropy of the mechanical properties of a polycrystal is a direct consequence of the anisotropy of the properties of each grain and of this crystallographic texture. Moreover, the reorientation of the grains during mechanical deformation of the polycrystal results in texture changes.

Another factor that makes zinc difficult to characterize is its hexagonal structure. Indeed, in general Hexagonal Close Packed (HCP) materials can be deformed by two different mechanisms: slip and twinning. Slip in the crystallographic planes is the principal mechanism, which is activated when the resolved shear stress reaches a critical value. This critical value is lower along close-packed planes due to the higher atomic density, and therefore slip along these planes is the preferential way to accommodate plastic deformation. The second mechanism, twinning, is also activated particularly at higher loads, along several directions of the crystal, and with a separate critical stress value. Twinning leads to a discrete rotation of the c-axis within the twinned volume, by an angle depending on the type of the activated twin system. Several twin families have been identified in HCP materials: (1 0-1 2), (1 0-1 - 3), (1 0-1 1), (1 1-2 - 4), (1 1-2 2), (1 1-2 1), with the activated twin mode(s) depending on the $c / a$ of the material.

Surprisingly few studies, if any, are devoted to the mechanical characterization and to the study of the anisotropic behavior of this class of materials as a function of the initial microstructure, despite the continuing widespread use of these materials. In his paper on ductility in polycrystalline metals [7], von Mises was the first to note that five independent slip systems were required to accommodate the strain requirements associated with an arbitrary homogenous plastic deformation. Metal plasticity would require a (nearly) traceless deformation rate tensor with only 5 independent components (i.e. unknowns), needing a system of 5 independent deformation mechanisms (equations). While this criterion is directly applicable to Face-Centered Cubic (FCC) and Body-Centered Cubic (BCC) materials, the fundamentals of the yielding and work hardening response for hexagonal metals are significantly more complex, mainly because the hexagonal lattice does not provide a sufficient number of geometrically equivalent slip systems to satisfy the Von Mises criterion for polycrystal deformation, which is very different from what is seen in the case of FCC and BCC lattices. Meanwhile, to accomplish the deformation, more than one crystallographic slip mode and/or twin mode must be activated. The exact deformation mechanisms in Hexagonal Close Packed (HCP) metals, dislocation motion on specific slip systems and activation of twinning, are not yet completely understood. The discussion in the previous paragraph basically implies that Zinc, as an HCP material, shows markedly anisotropic mechanical properties that depend on its initial textures, deformation mechanisms and critical shear stresses which, in turn, are different for different slip systems as well as the direction of the applied stress (e.g. asymmetry of twin activation) during mechanical loading. There are four possible slip systems, basal, prismatic and pyramidal $\langle a\rangle$ and pyramidal $\langle c+a\rangle$. In general, zinc exhibits deformation on several crystallographic slip and twin systems, with very different activation stresses for each system. The relative contributions of individual slip and twin modes strongly depend on temperature, loading conditions, alloying elements, crystallographic texture, and microstructure evolution. This is the main reason for zinc's anisotropic behavior. The differing volume fractions of twins during tensile and compressive loading leads to the alloy's tension-compression asymmetry. Nevertheless it can be noticed that basal and pyramidal $\langle c+a\rangle$ are more likely to be activated in tensile test [8].

Furthermore, zinc and its alloys are typical metals with HCP lattice structure with a $c / a$ of 1.856 , i.e. higher than that of an ideal structure $(c / a=1.632)$ and this leads to a higher than usual property dependence on the slip and twinning systems [9].

Currently, there is a dearth of systematic studies where crystallographic texture and grain anisotropy have been examined over a wide range of conditions. Knowledge of the active deformation mechanisms and the variation in their relative contribution as a function of these variables is required for accurately predicting the plastic response and texture evolution of zinc and its alloys. This is particularly important for the development of reliable material models for use in simulating forming processes with these materials, especially given the increase in applications of this class of materials.

The existing literature on mechanical modeling of the anisotropy of zinc alloys is, as expected, based on micro-mechanical approaches $[10,11]$. Micro-mechanical modeling provides a link between the microstructure of a material and its mechanical behavior, allowing us to quantify plastic deformation at the microstructural level. This approach is thus well-suited for simulations involving material texture and related anisotropy. A considerable amount of simulation has been performed using "physically based" models rather than simply fitting phenomenological behavior laws in the literature [10-20].

Zinc based alloys typically involve several deformation modes, including slip and twinning systems. These systems have different and unknown activation stresses that depend, usually in a non-unique manner, on the experimental approach used to study the texture as well as on the type of micro-mechanical model. We therefore need an accurate model to simulate its deformation under loading, including the large deformations typically encountered during forming processes. This model needs to be capable of not just describing the mechanical response of the material for a given texture, but also predicting how this texture would evolve with deformation.

Wang et al [21] compared the predictive capability of different polycrystal plasticity models using the predicted and experimental stress responses, observing that:

1. Self-consistent models with grain interaction stiffness halfway between the limiting Secant (stiff) and Tangent (compliant) approximations gave the best results.

2. The affine auto-coherent models using a self-consistent scheme yielded the best overall performance $[22,23]$.

As a result, they concluded that Secant and Tangent approximations were inappropriate for highly anisotropic materials like HCP polycrystals. Given that Zinc alloys are hexagonal polycrystals, and in light of the available evidence, we adopt the Visco-Plastic Self-Consistent (VPSC) approach developed by Lebensohn and others [24-27] which does not enforce either stress or strain equilibrium on the individual grains (unlike the Sachs and Taylor models) and is more appropriate for hexagonal materials [27].

The present paper is a contribution towards the development of a complete protocol for the characterization of Zn alloys by clarifying the physical mechanisms involved in the plastic deformation of rolled $\mathrm{Zn}$ $\mathrm{Cu}$-Ti sheets. The experimental portion of this work involves tensile testing of a $\mathrm{Zn}-\mathrm{Cu}$-Ti sheet along three directions to study its macroscopic mechanical behavior, and Electron Beam Scatter Diffraction (EBSD) to examine the microstructure i.e. texture evolution. The texture evolution is studied so as to shed some light on the fundamental 
mechanisms responsible for the plastic deformation, crystallographic slip or mechanical twinning, which is a pre-requisite for the micro-scale model.

The Visco-Plastic Self-Consistent (VPSC) model is considered to estimate the multiscale behavior of the rolled $\mathrm{Zn}$-Cu-Ti sheet, with the required material parameters such as the critical resolved shear stresses for the different slip and twin systems identified using an inverse analysis by comparing the stress-strain curves from uniaxial tensile testing along three different orientations $\left(0^{\circ} / \mathrm{RD}, 45^{\circ} / \mathrm{RD}\right.$ and $\left.90^{\circ} / \mathrm{RD}\right)$ along with the simulated macroscopic stress-strain curves along the same three directions.

The inverse problem is solved by optimization with the well-known Covariance Matrix Adaptation Evolution Strategy (CMA-ES) [28] evolutionary algorithm. Using the identified micro-scale parameters, we calculate the Lankford R-values followed by the Hill coefficients for the alloy by simulation. The simulated and experimental yield surfaces are compared. The identified microscale parameters are shown to correctly predict the texture evolution during tensile testing along the three directions. Finally, the simulated R-values are compared with those reported in the literature $[29,30]$.

In the following sections, we first present the material preparation, EBSD and other experimental techniques used followed by a description of the results obtained. Next we introduce the multi-scale modeling approach based on the VPSC paradigm. We then describe the solution procedure for the final inverse problem using the CMA-ES algorithm, followed by results obtained and a detailed discussion. The paper ends with concluding comments and recommendations for future work.

\section{Materials and experimental techniques}

In this section we describe the materials being characterized along with the main experimental tests used in this work.

\subsection{Materials}

We focus on commercial rolled sheets of $\mathrm{Zn}-\mathrm{Cu}$-Ti, purchased from Umicore. The desired mechanical properties of these rolled sheet materials are generally attained by alloying $\mathrm{Zn}$ with $0.1-0.2 \%$ copper and titanium [31], giving a $\mathrm{Zn}-\mathrm{Cu}-\mathrm{Ti}$ alloy. Up to approximately $1 \%$ of this copper addition is in the form of a solid solution in the $\mathrm{Zn}$ matrix and results in an increase in strength, hardness, and creep resistance.

On the other hand, due to the lower solubility of titanium (no more than $0.11 \%$ of Titanium in the alloy), titanium reacts with zinc and hard inter-metallic particles (stringers) of $\mathrm{TiZn}_{15}$ are formed [32] (within the $\mathrm{Cu}-\mathrm{Zn}$ solid solution) that are distributed parallel to the rolling direction. This inter-metallic phase decreases the grain size of the cast zinc, restrains the grain growth of the rolled zinc sheet at elevated temperatures. The reduction in grain size is because TiZn15 precipitates at grain boundaries, and so acts as a barrier to grain growth. Since the grain size is refined, the intermetallic phase volume fraction increases with $\mathrm{Al}$ increasing. The finer grain would create more grain boundaries, thus causing the alloy passivate more easily resulted in a reduced degradation rate. The smaller grain size enables a greater percentage of the surface to be covered with a protective Titania-Zn oxide film $[30,33,34]$. Such an inter-metallic phase expectedly affects the mechanical properties of the material (e.g. tensile strength, hardness). For example, the size and distribution of TiZn15 stringers (within the Cu-Zn solid solution) leads to substantial increase in creep resistance of the alloy [35].

We use a natural Zinc-based alloy in this work, i.e. without any coating. This alloy is fully Hexagonal Close-Packed (HCP) at room temperature and has the chemical composition given in Table 1. The initial thickness of the rolled sheets is $0.65 \mathrm{~mm}$.
Table 1

Chemical composition (\%) of the rolled $\mathrm{Zn}-\mathrm{Cu}-\mathrm{Ti}$ commercial zinc alloy.

\begin{tabular}{lllll}
\hline Materials & $\mathrm{Cu}$ & $\mathrm{Ti}$ & $\mathrm{Al}$ & $\mathrm{Zn}$ \\
\hline Natural Zinc & $\geq 0.08$ & $\leq 0.06$ & - & rest \\
\hline
\end{tabular}

\subsection{Experimental techniques}

\subsubsection{Uniaxial tensile testing}

A series of uniaxial tensile tests have been carried out for the zinc sheets, using testing specimens with a gage length of $30 \mathrm{~mm}$ and width of $10 \mathrm{~mm}$ each. These specimens were machined using a hyperbar water jet. The tests were performed on different specimens cut out from the materials at various orientations with respect to the rolling direction: $0^{\circ}, 45^{\circ}$ and $90^{\circ}$. The deformation was controlled by a high-resolution extensometer on a rather short measuring base. Each test was repeated 3 times and performed under quasi-static condition at strain rate of $10^{-3} \mathrm{~s}^{-1}$.

\subsubsection{Texture measurements by EBSD and SEM}

Electron Back Scatter Diffraction (EBSD) is used to locally characterize the microstructures, such as the average grain size, the crystallographic grain orientation, the local misorientation, etc. The microstructure has been observed using a Field Emission Electron Gun, Scanning Electron Microscope (FEG-SEM) ZEISS Sigma ${ }^{\mathrm{TM}}$ at $10 \mathrm{keV}$, with an integrated AMETEK-EDAX detector.

With an electron beam acceleration voltage of $25 \mathrm{kV}$ and a working distance of $20 \mathrm{~mm}$, the TSL OIM Data Collection Software ${ }^{\mathrm{TM}}$ records the Kikuchi patterns generated by the inelastic scatter of electrons in the specimen tilted at $70^{\circ}$. For fine analysis, we assume an initial step size of $1 / 5$ th of the average grain diameter, and progressively reduce this for more detail.

Sample preparation has been performed by mechanical polishing in this work, using a VibroMet 2 Vibratory Polisher.

In the OIM scan, the number of points required to determine a "grain group" (the Minimum Grain Size) has been set according to the characteristics of the microstructure, while the value chosen for the Grain Tolerance Angle (between grains) is equal to $5^{\circ}$. Only coherent twins are considered satisfying the following two criteria:

1. The orientation of the twin related to the parent through specific misorientations,

2. The twinning plane must be aligned with the boundary plane separating the twin from the parent.

The parent grain is defined as the entity with the most points measured in a direction.

The EBSD data was "cleaned up" to remove erroneous grains (e.g. with diameter less than 2 pixels) using statistical methods such as calculation of average grain size and grain boundaries rotation angle. Serial sectioning and other stereo-logical approaches were then applied to extract the complete boundary normal informations, in order to calculate both orientations as well as misorientations. To determine the activated slip systems, the Schmid factor (described in the Section 4) is calculated using OIM. We carry out a series of SEM observations on the material in "as-received" state as well as on samples deformed by uniaxial tension along different directions $\left(0^{\circ}, 45^{\circ}, 90^{\circ}\right)$ with respect to the rolling direction (RD).

In parallel, we use Digital Image Correlation techniques to confirm the rapid evolution of the strain field from uniform to very heterogenous. 


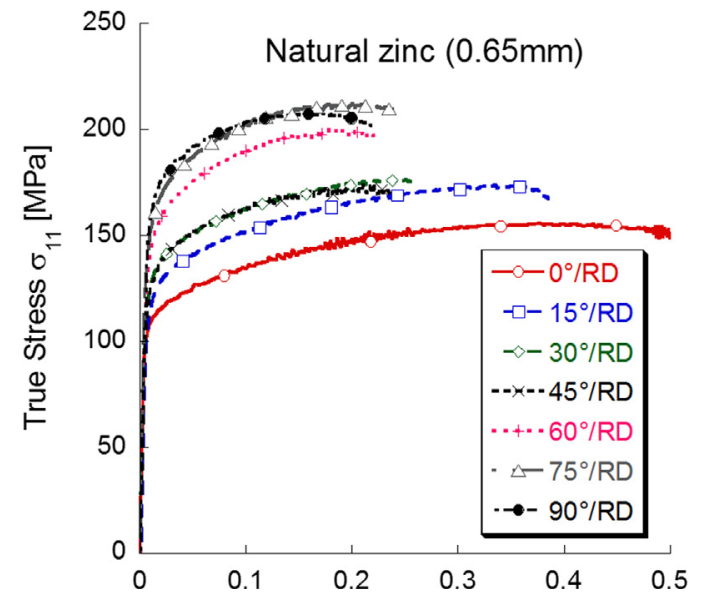

Fig. 1. Macro-scale tensile stress-strain curves for $0.65 \mathrm{~mm}$ Zn sheet.

\section{Experimental results}

\subsection{The macroscopic strain-stress curves}

Fig. 1 shows the strain-stress curves obtained using uni-axial tensile tests along the three directions. The material shows anisotropic behavior, as expected. The ductility decreases as the loading direction approaches the transverse direction (true stress over $200 \mathrm{MPa}$ for barely over $20 \%$ plastic strain) with maximum ductility observed along the rolling direction (a true stress of barely $150 \mathrm{MPa}$ for $50 \%$ strain). On the other hand, the strength is observed to increase as the loading direction approaches the transverse direction (TD). Therefore, three different loading orientations $\left(0^{\circ} / \mathrm{RD}, 45^{\circ} / \mathrm{RD}\right.$ and $\left.90^{\circ} / \mathrm{RD}\right)$ are considered to examine the macroscale behavior. By comparing these three groups of stress-strain curves, as seen in the Fig. 1, we clearly observe the anisotropic behavior of the considered material.

\subsection{The crystallographic texture evolution}

The regions of observation are shown in Fig. 2. We also note here, from the aforementioned DIC, that the strain field in the specimen is indeed non-uniform.

By comparing the Schmid factor maps for loading along different directions, it is possible to understand the relative contributions of different slip systems to deformation under different loading conditions. Based on the loading conditions and the Euler angles of the grains (obtained by EBSD) the Schmid factors of the 4 theoretically possible slip planes in one grain of the hexagonal material have been calculated. The plane with the largest value of Schmid factor is considered to be the primary slip plane. As already mentioned, in general, basal and pyramidal $\langle c+a\rangle$ are more likely to be activated in a tensile test [8]. From the Figs. 3 to 5, we see that along the rolling direction, basal slip is the most important while along $45^{\circ} / \mathrm{RD}$ and $90^{\circ} / \mathrm{RD}$, prismatic and pyramidal slips has respectively the higher possibility to be activated during the loading process rather than that of $0^{\circ} / \mathrm{RD}$. And therefore, as already observed by [8] basal and pyramidal $<c+a>$ slip systems will be considered in the material model.

As has been frequently mentioned in this paper, HCP materials exhibit deformation twinning to accommodate strains along the $c$ axis. Also the measurement of the twinning fraction is troublesome, due to the difficulty of identifying totally reoriented grains as twins. The EBSD analysis shows a substantial contribution to deformation by twinning, therefore it is logical to fit twinning parameters.

In case of Zinc based materials, the system that is more likely to activate is the (1 $0-12)$ system which causes contraction along the $c$ axis. However, in our SEM, we consider two other possible twin systems (1 $1-21)$ and (1 $1-2$ 2) in order to additionally estimate the twin volume fraction of both in the "as received" (and later the deformed) material.

Fig. 6 shows the identification of the twin region for the selected twin families. As expected, the dominant twin system belongs to the (1 $0-12$ ) family with a surface fraction of about $16 \%$, which is in good agreement with the result observed in the figure.

Keeping all these observations in mind, we decide to retain the deformation modes summarized in Table 2 for the micro-scale material model in the next section. This choice is in relative agreement with most of the published experimental works for similar materials (see Table 3)

\section{Multi-scale constitutive modeling}

During sheet metal forming involving very anisotropic metals, we are frequently unable to adequately describe the material's macroscopic behavior using a simple phenomenological model, and are forced to take the underlying physical mechanisms into account via a micromechanical model [22]. This model accounts for the effect of the crystallographic texture and its evolution on the macroscopic response during mechanical loading and deformation.

Simple polycrystal models of the last century include the Sachs [49] and Taylor models [50]. In our work, since elastic deformation as well as creep effects are negligible during metal forming, and so we adopt a visco-plastic model instead of elasto-plastic or viscoelastic models.

Lebensohn and Tome's Visco-Plastic Self-Consistent (VPSC) model [24] is based on [51], where the anisotropic behavior of the matrix was taken into account in a self-consistent scheme [52,53], i.e. a grain (inclusion) is assumed to be embedded in a Homogenous Effective Medium (HEM) whose behavior is given by the mean mechanical properties of the surrounding polycrystalline aggregate. This model provides a more accurate description of reorientation by twinning using a Volume Fraction Transfer scheme [25,26], and is better adapted to texture prediction in hexagonal materials [27].

In the present work, we adopt the affine formulation proposed by Masson et al. [23] (similar to the recommendation of Wang et al. [21]). The latter leads to predictions that are in-between the secant and the tangent approaches for high nonlinearity, and been successfully used to describe the behavior of hexagonal polycrystals [54].

\subsection{Microscale model}

The $\alpha$ superscript in the following subsection represents a quantity measured or calculated for slip/twinning system $\alpha$ for a grain (crystal). From Schmid's law, the resolved shear stress $\tau^{\alpha}$ is related to the grain's deviatoric Cauchy stress $\sigma_{g}^{\prime}$ :

$\tau^{\alpha}=\frac{1}{2}\left(\boldsymbol{s}^{\alpha} \otimes \boldsymbol{m}^{\alpha}+\boldsymbol{m}^{\alpha} \otimes \boldsymbol{s}^{\alpha}\right): \sigma_{g}^{\prime}=\boldsymbol{P}^{\alpha}: \sigma_{g}^{\prime}$

where $\boldsymbol{P}^{\alpha}$ is the second order Schmid tensor derived from EBSD measurements, $\boldsymbol{s}^{\alpha}$ and $\boldsymbol{m}^{\alpha}$ the slip direction and slip plane normal.

For cold deformation, the rate sensitivity of the flow stress is low, so the shear stress and slip rate may be approximated by:

$\dot{\gamma}^{\alpha}=\dot{\gamma}_{0}\left(\frac{\left|\tau^{\alpha}\right|}{\tau_{c}^{\alpha}}\right)^{n} \operatorname{sgn}\left(\tau^{\alpha}\right)$

where $\dot{\gamma}^{\alpha}$ is the shear strain rate, $n$ is the strain rate sensitivity exponent, $\dot{\gamma}_{0}$ is a reference shear strain rate, and $\tau_{c}^{\alpha}$ is the critical resolved shear stress (CRSS).

The plastic strain rate $\dot{\boldsymbol{\varepsilon}}^{p}$ is given by considering that the velocity gradient tensor $\boldsymbol{L}^{p}$ is the result of the accumulation of shear in all of the $N_{s}$ active slip and twinning systems of the crystal:

$\boldsymbol{L}^{p}=\boldsymbol{D}^{p}+\boldsymbol{\Omega}^{p}=\dot{\boldsymbol{F}}^{p}\left(\boldsymbol{F}^{p}\right)^{-1}=\sum_{\alpha=1}^{N_{s}} \dot{\gamma}^{\alpha}\left(\boldsymbol{s}^{\alpha} \otimes \boldsymbol{m}^{\alpha}\right)$ 

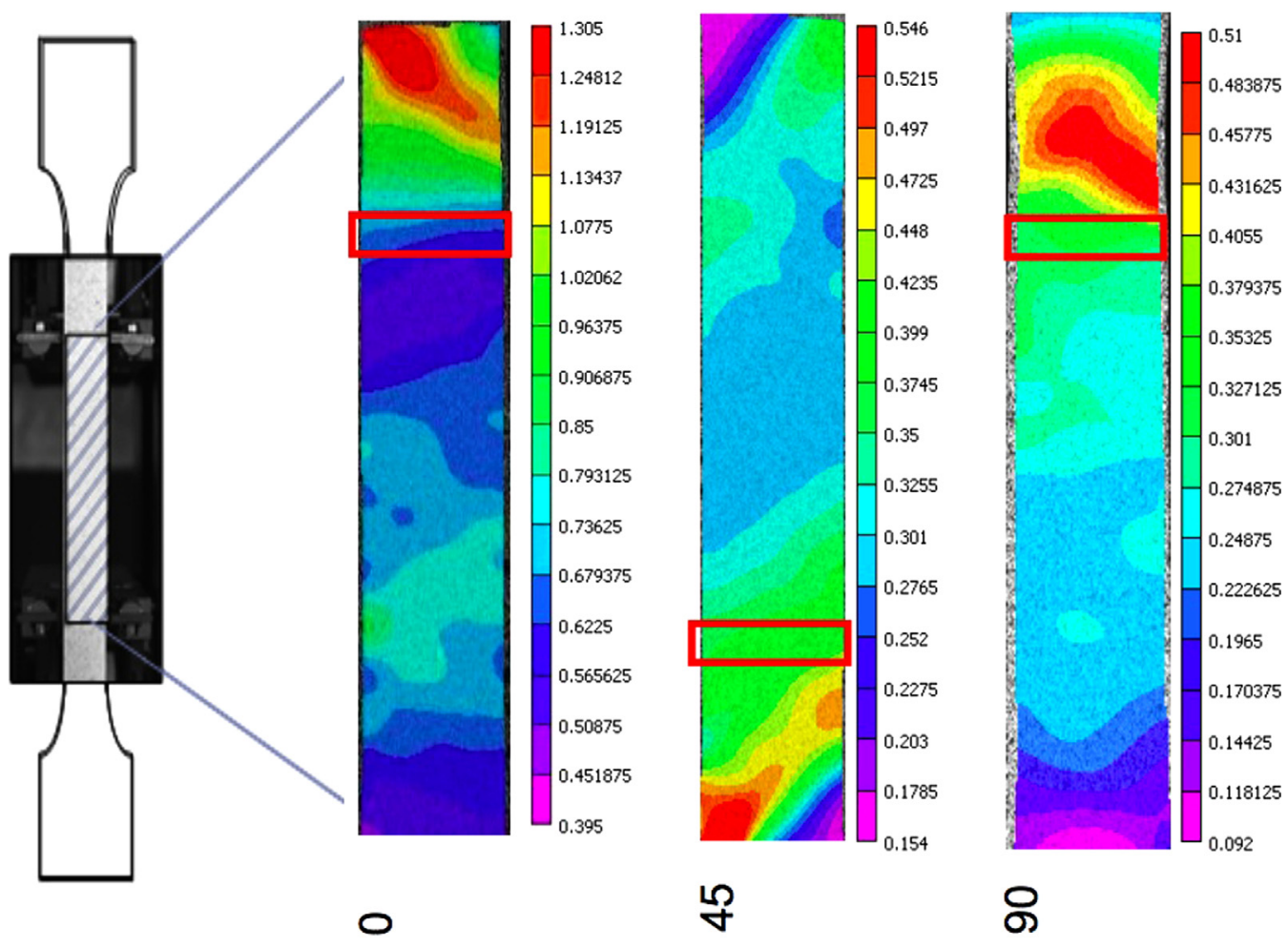

Fig. 2. Region for EBSD measurement showing the strain distribution for deformed natural zinc ( $0.65 \mathrm{~mm}$ thickness).

thus giving the stretching rate tensor (and viscoplastic strain rate):

$\dot{\boldsymbol{\varepsilon}}^{v p}=\boldsymbol{D}^{p}=\left(\sum_{\alpha=1}^{N_{s}} \dot{\gamma}^{\alpha}\left(\boldsymbol{s}^{\alpha} \otimes \boldsymbol{m}^{\alpha}\right)\right)^{\text {sym }}=\sum_{\alpha=1}^{N_{s}} \dot{\gamma}^{\alpha} \boldsymbol{P}^{\alpha}$

and rotation tensors $\boldsymbol{\Omega}$ and $\mathbf{\Omega}^{p}$ :

$\mathbf{\Omega}=\frac{1}{2}\left(\boldsymbol{L}-\boldsymbol{L}^{T}\right), \mathbf{\Omega}^{p}=\sum_{\alpha=1}^{N_{s}} \frac{1}{2}\left(\boldsymbol{s}^{\alpha} \otimes \boldsymbol{m}^{\alpha}-\boldsymbol{m}^{\alpha} \otimes \boldsymbol{s}^{\alpha}\right), \mathbf{\Omega}^{*}=\mathbf{\Omega}-\mathbf{\Omega}^{p}$

$\boldsymbol{D}$ is related to the Jaumann derivative of $\sigma_{g}$, giving the viscoplastic constitutive equation relating $\sigma_{g}$ and plastic strain rate by combining the previous equations:

$$
\dot{\boldsymbol{\varepsilon}}_{g}^{v p}=\dot{\gamma}_{0} \times \sum_{\alpha=1}^{N_{S}} \boldsymbol{P}^{\alpha}\left(\frac{\left|\boldsymbol{P}^{\alpha}: \sigma_{g}^{\prime}\right|}{\tau_{c}^{\alpha}}\right)^{n} \operatorname{sgn}\left(\boldsymbol{P}^{\alpha}: \sigma_{g}^{\prime}\right)
$$

Finally, we assume that each individual slip/twinning system has its own extended 4-parameter Voce hardening law linking the CRSS with the accumulated shear $\Gamma_{g}=\sum_{\alpha=1}^{N_{s}}\left|\gamma^{\alpha}\right|$ in the grain (over all slip/twinning systems):

$\tau_{c}^{\alpha}=\tau_{0}^{\alpha}+\left(\tau_{1}^{\alpha}+\theta_{1}^{\alpha} \Gamma_{g}\right)\left(1-e^{-\frac{\Gamma_{g}\left|\theta_{0}^{\alpha}\right|}{\tau_{1}^{\alpha}}}\right)$

As explained previously, we have chosen 2 active slip and 1 active twinning mode for the alloy studied. The strain rate used is $10^{-3} \mathrm{~s}^{-1}$, and the strain rate sensitivity exponent is 20 .

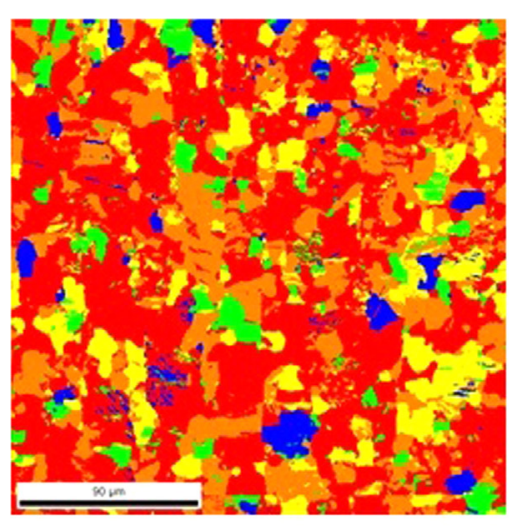

(a)

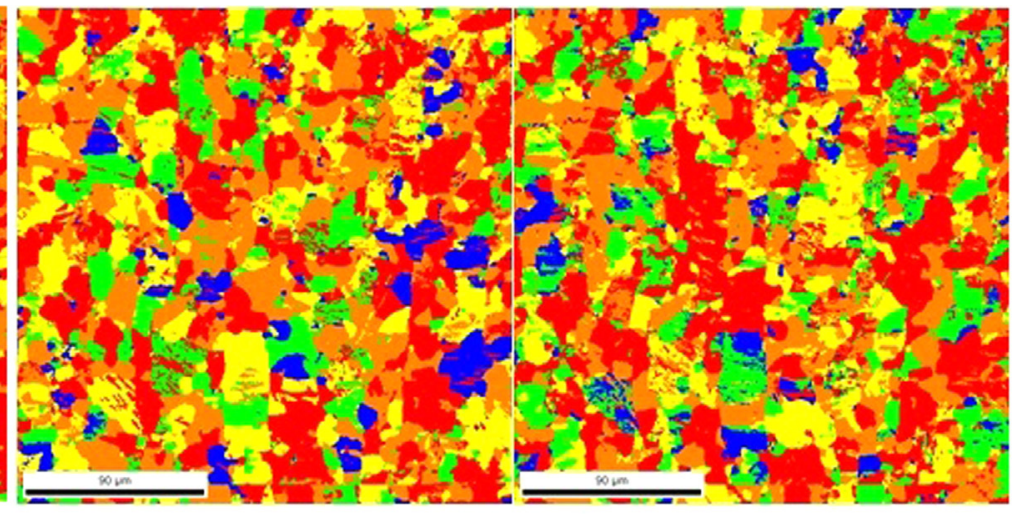

(b) (c)

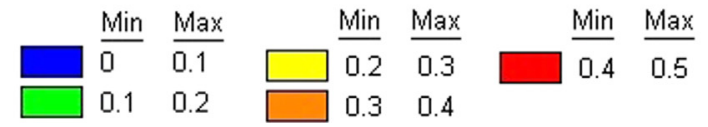

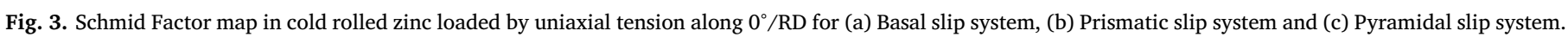




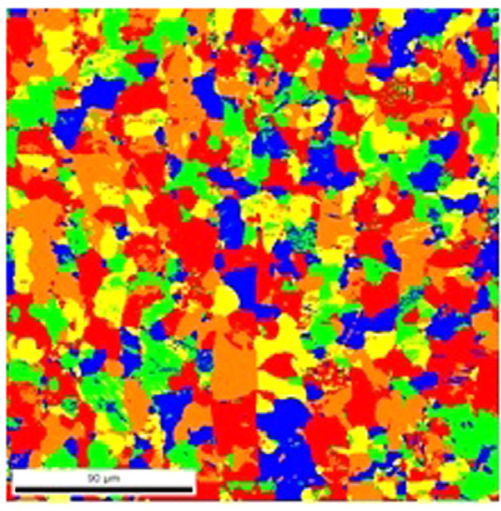

(a)

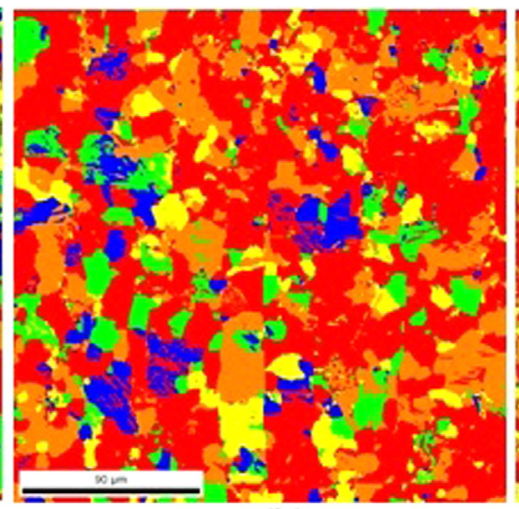

(b)

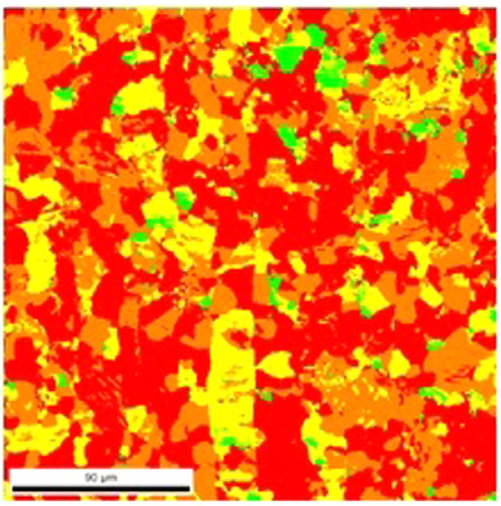

(c)

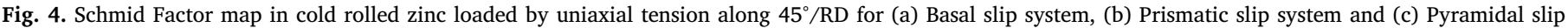
system.

\subsection{Mesoscale and macroscale model}

Here, we simulate the macro-scale behavior for comparison with the experimental results to identify the micro-scale parameters using inverse analysis. The strain hardening of the macroscopic material is controlled by the Voce hardening parameters giving the critical shear stress as a function of the accumulated deformation for each of the slip/ twinning systems, for each grain (crystal). To obtain the macroscopic behavior, the VPSC approach solves the equivalent inclusion Eshelby problem (single crystal) for an elliptical inclusion in an infinite matrix, and iteratively forcing the polycrystal i.e. composite stress and strain to coincide with the volumetric averages of the same over the grains, i.e., self-consistent homogenization, giving the macroscopic behavior of the material.

This gives concentration equations for the Cauchy stress tensor. Since the averaged stress tensor equals the macroscopic stress tensor, we obtain self-consistent equations for the aggregate moduli. The scheme reproduces the macroscopic deviatoric stress $\widetilde{\boldsymbol{S}}$ and strain rate $\widetilde{\boldsymbol{D}}^{p}$ in the polycrystal from the grain equivalents $\sigma_{g}^{\prime}$ and $\dot{\varepsilon}_{g}^{v p}$ for the current texture at each step using the interaction laws:

$$
\begin{aligned}
& \widetilde{\boldsymbol{D}}^{v p}-\dot{\boldsymbol{\varepsilon}}_{\mathrm{g}}^{v p}=\boldsymbol{M} .\left(\boldsymbol{\sigma}_{g}^{\prime}-\widetilde{\boldsymbol{S}}\right) \\
& \text { where } \boldsymbol{M}=n^{e f f}(\boldsymbol{I}-\boldsymbol{E})^{-1} \boldsymbol{E} \overline{\boldsymbol{M}}
\end{aligned}
$$

iteratively starting with the initial textures for the "as received" material. Morphology, texture and hardening are updated using an incremental implicit scheme at each step until convergence of the algorithm, at which point we obtain the uniaxial true stress-strain curves in the three different directions $0^{\circ}, 45^{\circ}$ and $90^{\circ}$.

The final stage, determining the optimal micro-scale parameter set that will lead the best agreement with the experimental data for the specimen, will be described in the next section.

\section{Inverse analysis and parameter identification}

The parameters required for calibrating the micro-scale model are the 4 parameters of the Voce hardening law $\left(\tau_{0}^{\alpha}, \tau_{1}^{\alpha}, \theta_{0}^{\alpha}\right.$ and $\left.\theta_{1}^{\alpha}\right)$, for each of the deformation modes considered (i.e., $\alpha=1 . .3$ ). These parameters need to be extracted using the experimental data obtained from the uniaxial tensile tests in the 3 different directions. This is accomplished by finding the set of micro-scale material parameters that produces the macro-scale tensile curves that are closest to the experimental tensile curves, using inverse analysis [55-57].

As has been explained in the previous sections, the 3 modes correspond to 2 slip deformation modes (Basal and Pyramidal $<c+a>$ (also called $\pi_{2}$ )) and a single tensile twinning system, as given in Table 2 . This gives a total of $3 \times 4=12$ total micro-scale parameters need to be identified in the inverse problem, $\tau_{0}^{1}, \tau_{1}^{1}, \theta_{0}^{1}, \theta_{1}^{1}, \tau_{0}^{2}, \tau_{1}^{2}, \theta_{0}^{2}, \theta_{1}^{2}, \tau_{0}^{3}, \tau_{1}^{3}, \theta_{0}^{3}$ and $\theta_{1}^{3}$, collected in a vector $\bar{V}$, exponent 1,2 and 3 corresponding respectively to basal, Pyramidal $\pi_{2}$ slip systems and tensile twinning system.

\subsection{Tensile test simulation}

Uniaxial tensile loading on a $0.65 \mathrm{~mm}$ natural zinc sheet along three different orientations has been simulated using the approach given in

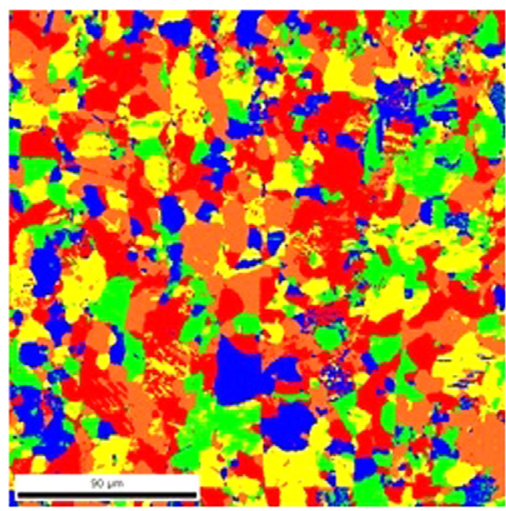

(a)

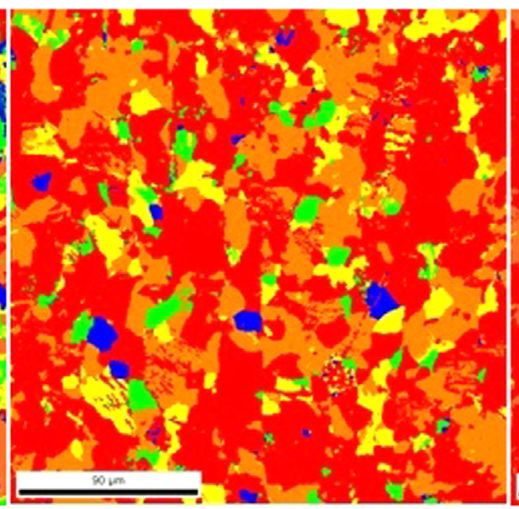

(b)

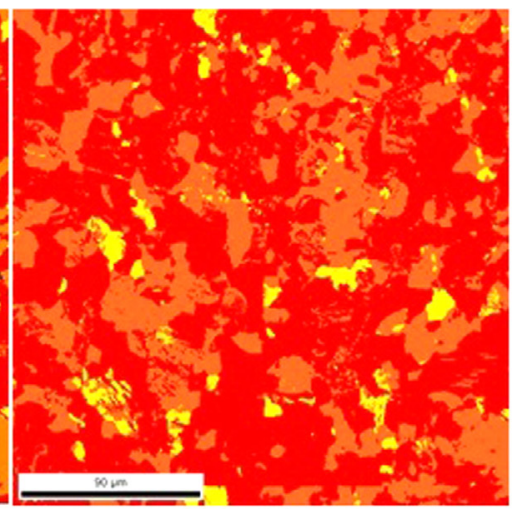

(c)

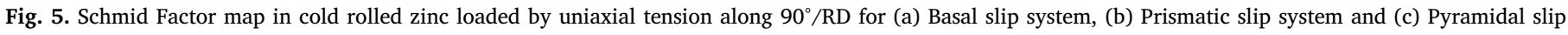
system. 

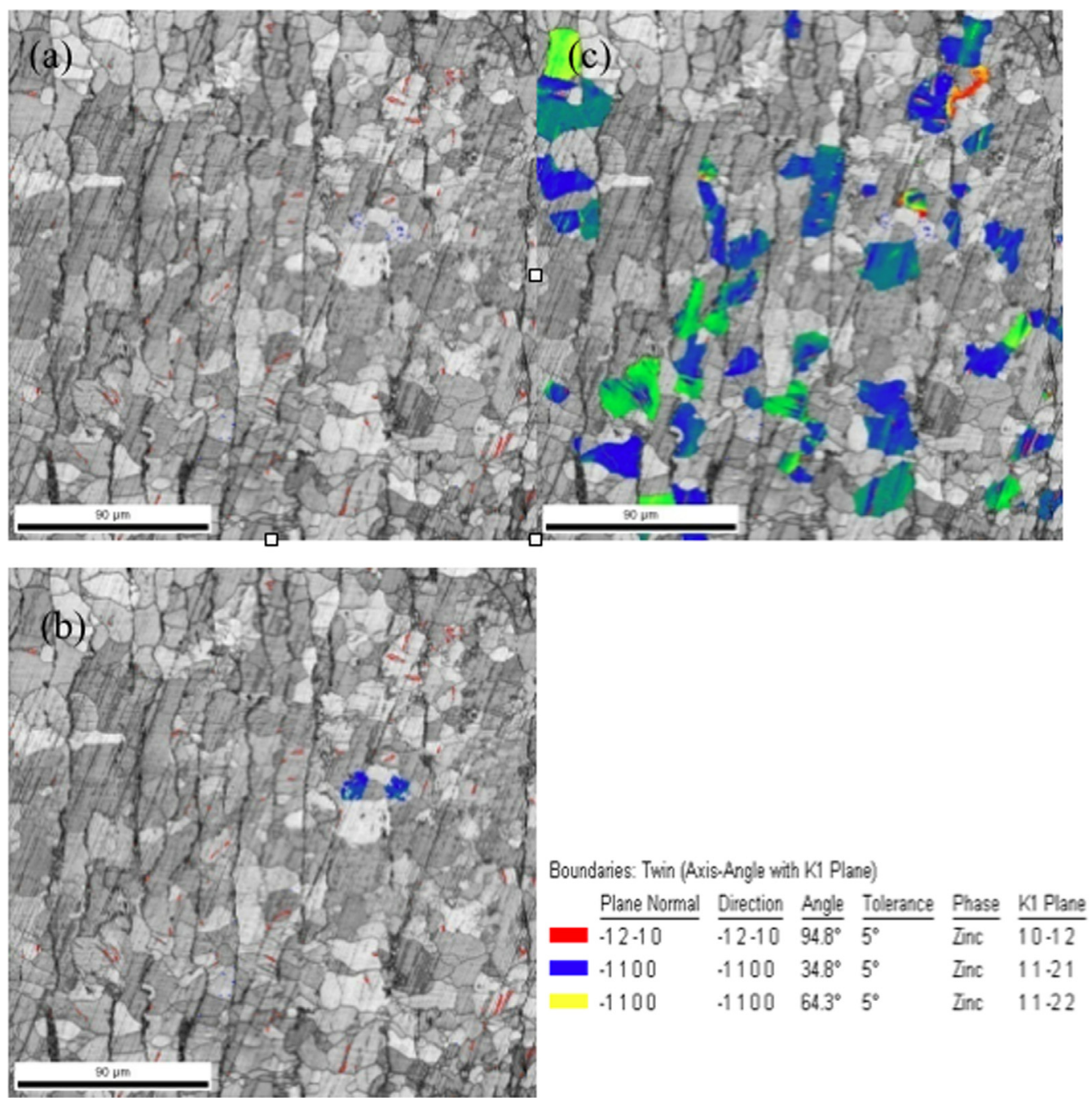

Fig. 6. Grains with twin boundaries marked (colored region): (a) grains with (1 1-2 2) twin boundaries, (b) grains with (1 1-2 1) twin boundaries, (c) grains with (1 0-1 2) twin boundaries.

Table 2

Deformation modes to be considered in the microscale model.

\begin{tabular}{|c|c|c|c|}
\hline System & Basal & Pyramidal $\pi 2$ & Tensile twinning \\
\hline Number of planes & 1 & 6 & 6 \\
\hline Number of directions & 3 & 6 & 6 \\
\hline Double planes & 3 & 6 & 6 \\
\hline Slip plane \& & $\left(\begin{array}{llll}0 & 0 & 0 & 1\end{array}\right)$ & $(2-1-12)$ & $\left(\begin{array}{llll}1 & 0 & -1 & 2\end{array}\right)$ \\
\hline Slip direction & $<2-1-10>$ & $<-2113>$ & $<-10011>$ \\
\hline
\end{tabular}

the previous section, with a combination of strain and stress boundary conditions.

\subsection{Inverse problem}

Let $\bar{V}_{\text {opt }}$ represent the set of identified material parameters. The optimization problem is formally presented as follows:

$$
\begin{aligned}
& \bar{V}_{\text {opt }}=\operatorname{Argmin}_{\bar{V} \in \mathscr{S}}\|J(\bar{V})\| \\
& =\operatorname{Argmin}_{\nabla \in \mathscr{S}}\left\|\bar{\sigma}_{\text {int }}(\bar{V})-\bar{\sigma}_{\text {exp }}\right\| \text { where } \mathscr{S} \subset \mathscr{R}_{+}^{12}
\end{aligned}
$$

where the objective function $J: \mathscr{S} \rightarrow \mathscr{R}$ is based on the pointwise difference between the theoretical and the experimentally obtained curves of true stress versus true strain $\left(\bar{\sigma}_{\text {calc }}, \bar{\varepsilon}_{\text {calc }} \in \mathscr{R}^{n c}\right.$ and $\left.\bar{\sigma}_{\text {exp }}, \bar{\varepsilon}_{\text {exp }} \in \mathscr{R}^{n e}\right)$ for uniaxial tensile loading along the 3 directions $0^{\circ}, 45^{\circ}$ and $90^{\circ}$, and $\sigma_{\text {int }}^{i}(\bar{V})=\widetilde{\sigma}\left(\varepsilon_{\text {exp }}^{i}, \bar{V}\right)$ is simply the vector of theoretical stress values
Table 3

Relative activity of different modes reported in the literature

\begin{tabular}{|c|c|c|c|c|c|c|c|}
\hline Material & $\tau_{\text {bas }}$ & $\tau_{p r i}$ & $\tau_{p y r 2}$ & $\frac{\tau_{\text {bas }}}{\tau_{p r i}}$ & $\frac{\tau_{\text {bas }}}{\tau_{\text {pyr } 1}}$ & $\frac{\tau_{\text {bas }}}{\tau_{p y r 2}}$ & $\frac{\tau_{\text {bas }}}{\tau_{\text {twin }}}$ \\
\hline Zinc single crystal & 0.28 & & & & & & \\
\hline Zinc single crystal & 0.1 & & & & & & \\
\hline $\begin{array}{l}\mathrm{Zn}+0.02 \% \mathrm{Al} \\
\text { single crystal }\end{array}$ & 0.5 & & & & & & \\
\hline Zinc single crystal & 0.3 & & $10-15$ & & & & \\
\hline Zinc single crystal & & & 6 & & & & \\
\hline Zinc single crystal & 0.5 & & & & & & \\
\hline Zinc single crystal & 0.14 & 3 & & & & & \\
\hline Zinc polycrystal & & & & & & $1: 7$ & \\
\hline Zinc polycrystal & & & & & & $1: 2$ & \\
\hline $\begin{array}{l}\mathrm{Zn}+0.16 \% \mathrm{Cu}+0.076 \\
\text { \%Ti polycrystal }\end{array}$ & & & & 1:15 & & 1:10 & $1: 30$ \\
\hline $\begin{array}{l}\mathrm{Zn}+0.165 \% \mathrm{Cu}+0.07 \\
\% \mathrm{Ti} \text { polycrystal }\end{array}$ & & & & 1:15 & $1: 30$ & $1: 10$ & \\
\hline $\begin{array}{l}\mathrm{Zn}+0.2 \% \mathrm{Al}+0.01 \\
\% \mathrm{Fe} \text { polycrystal }\end{array}$ & 1.5 & 22.5 & 15 & & & & $1.5 / 25$ \\
\hline $\mathrm{Zn}$-Ti $0.8 \mathrm{~mm}$ sheet & & & & $1: 15$ & & $1: 10$ & \\
\hline $\begin{array}{l}\mathrm{Zn}+0.1 \% \mathrm{Ti} \\
\text { single crystal }\end{array}$ & $\begin{array}{l}7.3- \\
12.2\end{array}$ & & & & & & \\
\hline
\end{tabular}
$[36,37,8,38-43,30,44,1,45,46,11,47,48]$. 


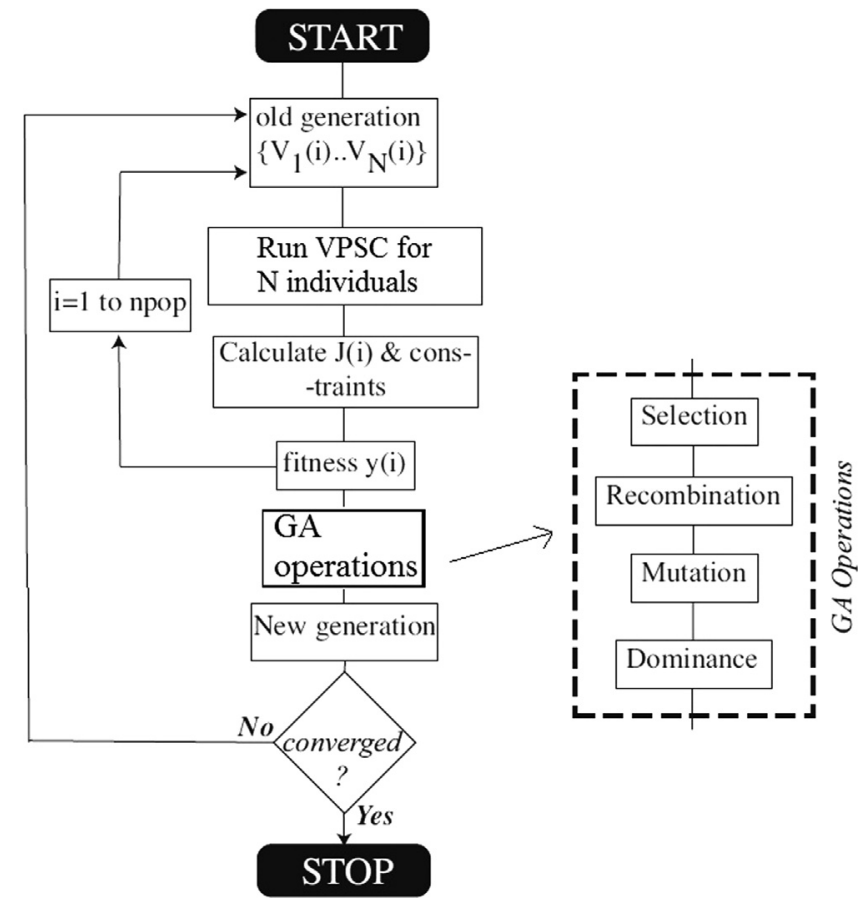

Fig. 7. (a) Full procedure for the identification (b) Evolutionary algorithm for the inverse problem.

interpolated at the experimentally obtained strain points $\bar{\varepsilon}_{\text {exp }}$ obtained by Diffuse Approximation [58] (since $n c \neq n e$ ).

$\widetilde{\sigma}\left(\varepsilon_{\text {exp }}^{i}, \bar{V}\right)=\bar{p}\left(\varepsilon_{\text {exp }}^{i}\right)^{T} \bar{a}\left(\varepsilon_{\text {exp }}^{i}, \bar{V}\right)$

where $\bar{p}(\varepsilon)=\left[1, \varepsilon-\varepsilon_{\text {exp }}^{i},\left(\varepsilon-\varepsilon_{\text {exp }}^{i}\right)^{2} \ldots\right]^{T}$ is a vector of monomials and the vector $\bar{a}$ is determined using:

$\left[\widetilde{\sigma}\left(\varepsilon_{\text {exp }}^{i}\right), \ldots\right]=\left[\mathbf{P}\left(\bar{\varepsilon}_{\text {calc }}\right)^{T} \mathbf{W P}\left(\bar{\varepsilon}_{\text {calc }}\right)\right]^{-1}\left[\mathbf{P}\left(\varepsilon_{\text {calc }}\right)^{T} \mathbf{W}\right]\left\{\bar{\sigma}_{\text {calc }}\right\}$

and $\mathbf{W}$ is a diagonal matrix obtained with an appropriate weighting function $w(\varepsilon)$ giving:

$\mathbf{W}=\operatorname{diag}\left(w\left(\varepsilon-\varepsilon_{\text {exp }}^{1}\right), w\left(\varepsilon-\varepsilon_{\text {exp }}^{2}\right) \ldots . w\left(\varepsilon-\varepsilon^{n} c_{\text {exp }}\right)\right)$

The parameters are fitted in several stages, using different sets of data to fit different parameters, independently or simultaneously. The whole procedure can be seen in Fig. 7(a). As shown, at the very beginning we try to fit the strain-stress curves of three loading directions $\left(0^{\circ} / \mathrm{RD}, 45^{\circ}\right.$ / $\mathrm{RD}$ and $90^{\circ} / \mathrm{RD}$ ) independently using the simplex algorithm to identify the parameters [59], which means three groups of parameters are found. Afterward, the average of these three groups of parameters is adopted as the initial input parameters, and a stochastic algorithm for the treatment of non-linear non-convex optimization problems in continuous domain CMA-ES (Covariance Matrix Adaptation Evolution Strategy) is used to obtain the best fitted parameters simultaneously. The evolutionary optimization approach is illustrated in Fig. 7(b).

In this evolutionary algorithm, new individuals (candidate solutions $\left.V_{1} . . V_{g}\right)$ i.e., the new generation are generated by the operations of crossover and mutation of the parents in the current generation. Next, some of these individuals are selected as parents in this next generation based on their fitness $f_{i}=J\left(\bar{V}_{i}\right)$. In this way, the fitness levels of the population as a whole continuously improve with each additional generation. The process is iteratively repeated until convergence.

\section{Results and discussion}

By solving the inverse problem for the $\mathrm{Zn}$ sheet as described in the previous section, we obtain the set of parameters, shown in Table 4, and we observe a relatively good fit between the experimental results and
Table 4

Identified micro-scale Voce parameters for all 3 deformation modes.

\begin{tabular}{llllll}
\hline$\alpha$ & Mode & $\tau_{0}^{\alpha}$ & $\tau_{1}^{\alpha}$ & $\theta_{0}^{\alpha}$ & $\theta_{1}^{\alpha}$ \\
\hline 1 & Basal & 1 & 1.6 & 250 & 3.31 \\
2 & Pyramidal $\pi_{2}$ & 47.94 & 51.54 & 4500 & 3.17 \\
3 & Twinning & 106.25 & 4.408 & 525.61 & 4.46 \\
\hline
\end{tabular}

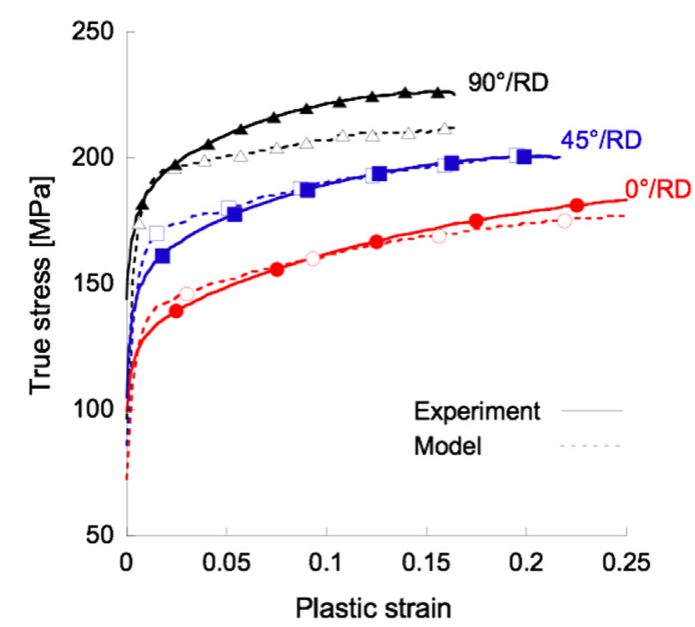

Fig. 8. Comparison of simulations with the identified micro-scale parameters and experiment.

multi-scale simulation (using the approach presented earlier), as will be seen in this section.

To better examine these parameters, we investigate the activation of deformation modes and textures after loading. The simulated textures will be compared to the experimental ones to draw a clear conclusion.

\subsection{Tensile curves}

The comparison of the macroscopic tensile curves obtained by simulation using the "best fit" identified micro-scale slip/twinning parameters and the experimental tensile curves is shown in Fig. 8. We observe good agreement between the experimental data and simulations, the agreement for loading along $0^{\circ} / \mathrm{RD}$ and $90^{\circ} / \mathrm{RD}$ being the best and worst respectively. For the $90^{\circ} / \mathrm{RD}$ loading, a good agreement between the curves is found until we reach a plastic strain of $\approx 3 \%$, after which the simulated strain-stress curves show a lower trend compared to the experimental curves. Overall, the model appears to adequately capture the hardening behavior of the alloy.

It is instructive to note the effect of different deformation modes on mechanical behavior during mechanical loading. Basal slip $\left(\begin{array}{llll}0 & 0 & 0 & 1\end{array}\right)<1$ $120>$ is the principal mode seen in zinc when the applied stress is along a random direction. First order Pyramidal slip $\left\{\begin{array}{lll}1 & 0 & 1-0\end{array}\right\}<1-120$ $>$ is typically seen when basal slip is either impossible, or when the applied load is in OR perpendicular to the basal plane. For zinc alloys, prismatic and pyramidal slips generally show greater activity at higher temperatures. The first 3 slip modes have the same slip direction (type $\left.<\begin{array}{llll}1 & 2 & 0\end{array}\right\rangle$ ) and only second order pyramidal slip $\left\{\begin{array}{lllll}1 & 1 & 2 & 2\end{array}\right\}<1-1 \quad 2 \quad 3>$ has an out-of-basal plane direction allowing the alloy to accommodate perpendicular strains. Twinning (tension twinning and compression twinning) may be assumed to be similar to a shear along a plane of type $\left(\begin{array}{llll}1 & 0 & 1 & 2\end{array}\right)$ along the $\left[\begin{array}{llll}1 & 0 & 1 & 1\end{array}\right]$ direction. It does not induce any significant strains [60], rather it simply modifies the crystal orientation to facilitate additional slip before rupture.

We need to add here that it is risky to attempt to reverse identify the hardening coefficients for a pre-determined set of deformation modes directly from the macroscopic tensile curves, with NO information whatsoever of the fundamental physics of the microscale deformation. 


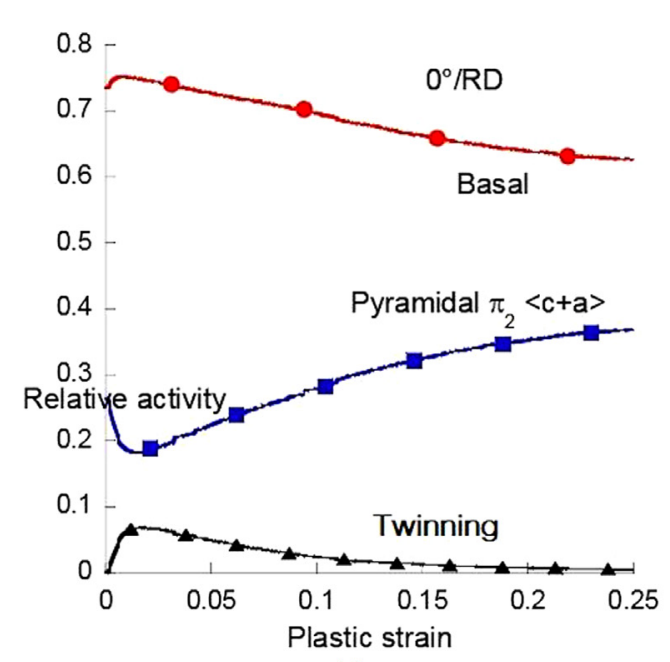

(a)

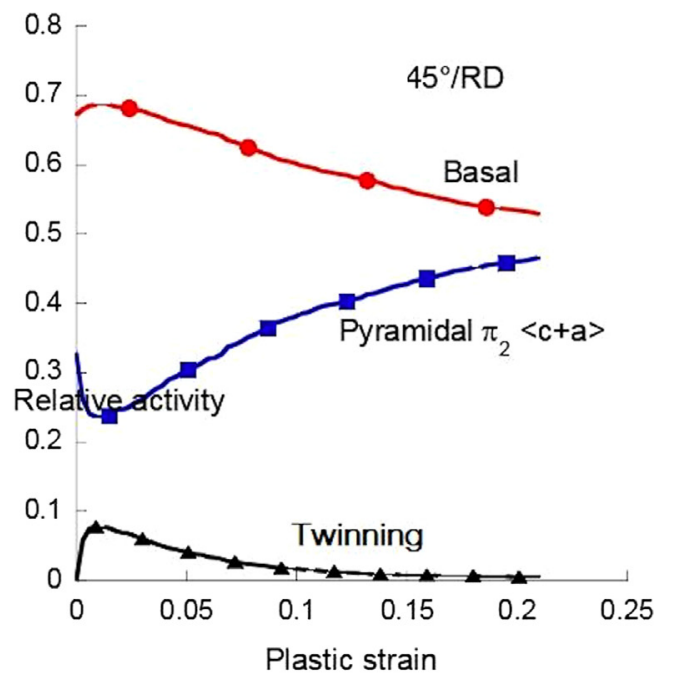

(b)

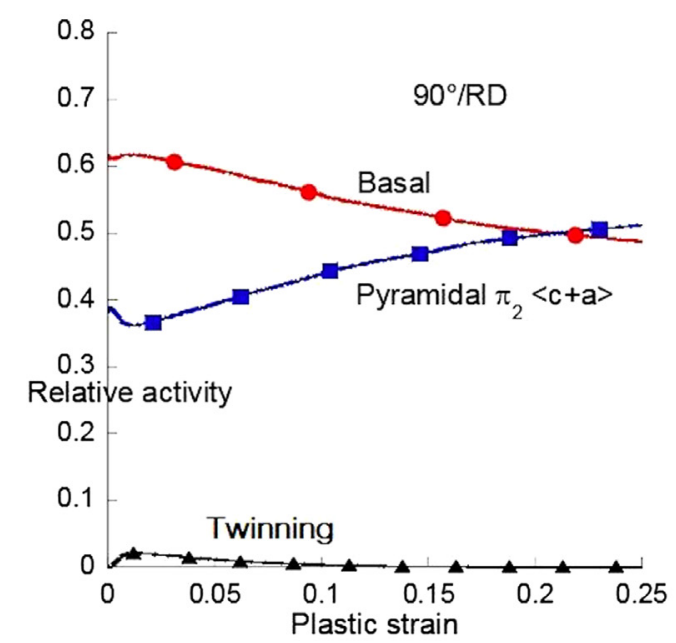

(c)

Fig. 9. Activation of deformation modes during simulated tensile loading along (a) $0^{\circ} / \mathrm{RD}$, (b) $45^{\circ} / \mathrm{RD}$ and (c) $90^{\circ} / \mathrm{RD}$.

This is because the inverse problem in question is inherently ill-posed. Simply put, various combinations of deformation modes could mathematically yield the same cumulative strain ergo the same macroscopic tensile behavior. This means that we either constrain the identification problem in hardening coefficient space to purely physically-reasonable values OR a priori determine the deformation modes active in the specimen under loading (using texture evolution prediction) and use that to "guide" the identification process, so as to obtain solutions that respect the fundamental physics of deformation for the specimen.

\subsection{Activation of deformation modes}

The activity of each of the three active deformation modes is shown in Figs. 9(a) to 9(c).

We see that for the loading direction along $0^{\circ} / \mathrm{RD}$, the model predicts that most of the deformation is accommodated by basal slip, followed by 2 nd order pyramidal slip (at the beginning). The percentage of basal slip system activity percentage decreases with strain, eventually dropping below that of 2 nd order pyramidal slip.

Meanwhile, during loading along $45^{\circ} / \mathrm{RD}$ and $90^{\circ} / \mathrm{RD}$, the activation shows a similar trend as that seen during loading along $0^{\circ} / \mathrm{RD}$, the only difference being the 2nd order pyramidal slip system activity that becomes more important (although lower than basal slip system activity). Twinning has approximately the same activity in all three loading conditions.

These observations are in good agreement with the results obtained by Philippe et al. [48] who reported the activation of basal slip, followed by pyramidal $\pi_{2}$ slip and finally twinning.

The percentage of twinning activity is seen to decrease with strain. This would appear to contradict the relatively recent (and very relevant) observation by Hou et al. [61]. However, Hou's result was on a Mg alloy with a $\mathrm{c} / \mathrm{a}(\approx 1.6)$ very different from our Zinc alloy (much higher $\approx 1.9$ ) in this work. More importantly, for the alloy chosen by Hou, the initial basal texture (c-axis oriented along ND) favors deformation by twinning rather than the other modes (basal and pyramidal), as seen by the rotation of c-axis from ND to TD. In our case, due to the initial texture and the loading conditions, basal activates first, then twinning activity rises very sharply initially and quickly "saturates" and then drops off, while pyramidal activity steadily increases as deformation increases. This scenario is in agreement with most of the published experimental works for similar texture (see Table 3).

It is important to note that the drop off in twinning activity in our Zn alloy is NOT due to "detwinning" in any way, but rather a reorientation of grains to a new configuration (i.e. texture) that does not favor twinning.

That being said, we have made (in our numerical model) the assumption that the Voce hardening coefficients remain constant 

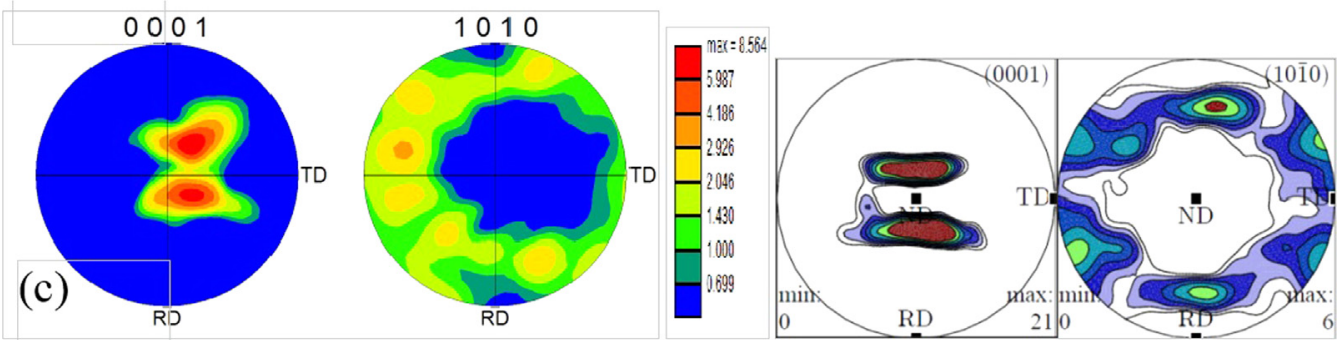

Fig. 10. Comparison of texture obtained by experiments (left) and simulations (right) for tensile loading along $0^{\circ} / \mathrm{RD}$ up to strain of $60 \%$.

throughout the deformation, which could potentially affect the results (for the evolution of system activity).

Finally, we feel there is not enough literature on twinning activity in Zinc alloys to reach any general conclusions. That is why we examine the texture evolution prediction here to further augment the quality of the identified micro mechanical hardening parameters, otherwise one could very easily lead to scenarios that would "fit" the macroscopic tensile curves without correctly describing the underlying physical reality $[18]$.

\subsection{Texture comparisons}

Figs. 10 to 12 compare the textures obtained using EBSD characterization with those predicted by the multi-scale modeling approach. The MTEX toolbox in MATLAB has been used to plot all the pole figures in this subsection.

We compare the deformed textures from experiment and VPSCbased simulation using the identified parameter set, under nearly the same amount of strain $\left(0^{\circ} / \mathrm{RD} \approx 60 \%, 45^{\circ} / \mathrm{RD} \approx 35 \%, 90^{\circ} / \mathrm{RD} \approx 30 \%\right)$ in Figs. 10 to 12.

The pole figures show a relatively good agreement on loading along $0 \% / \mathrm{RD}$ and $90^{\circ} / \mathrm{RD}$ condition, as expected, since the texture evolution is governed by the activated deformation modes in the loading process.

This basically means that the model successfully describes the activation of slip and twinning modes during uniaxial tension testing, at least for loading along $0 \% / \mathrm{RD}$ and $90^{\circ} / \mathrm{RD}$. The quality of the solution for loading along $45^{\circ} / \mathrm{RD}$ is not nearly as good as the other two, since for the experimental textures, the positions of the poles shift along the rolling direction (compared to the initial texture) while, in the simulated textures, the poles remain split from the center of the figure along the rolling direction. That said, in both cases 2 poles (i.e., highest intensity) are observed.

\subsection{Lankford R-values and Hill coefficients}

In order to determine if the identified micro-scale parameters may be applied to more general processes than those used for the fitting procedure, we next simulate the Lankford R-values and compare them with the reported experimental values in the literature. The Lankford value (also called $\mathrm{R}$-values), i.e., the plastic strain ratio $\left(\varepsilon_{22}^{p} / \varepsilon_{33}^{p}\right)$, is a measure of the plastic anisotropy of a rolled sheet metal for loading along a given direction.

It is known that the degree of planar anisotropy in the zinc is very different from that seen in other HCP materials (e.g., pure titanium or magnesium based materials). In typical HCP materials, deformation is mostly by $<11-20>$ slip thus allowing for higher R-values. R-values $>1$ indicate a higher resistance to thinning when the material is subjected to biaxial tensile stresses in the plane of the sheet. This translates to better formability when different parts of the blank are subjected to stretch-forming and radial drawing.

On the other hand, the R-values (i.e., the Lankford coefficient) for Zn-Cu-Ti rolled sheets are very low $(<1)$, which implies a low resistance to thinning (at least during monotonic loading). The high uniform elongations observed during tensile testing indicate that the deformation is mainly compensated by a significant thickness reduction along the entire gauge area.

Using the modeling approach described previously, we can calculate the R-values from the given texture, by simulating a series of tensile tests in the texture plane, along a series of directions "probed" at angular increments of $5^{\circ}$ from RD to TD.

The result obtained is compared with experimental results reported $[29,30]$ on a similar material in Fig. 13(a). From the curves, it is clear that the simulated results accurately describe the trend in the $R$ value's evolution when loading along different directions ranging from $\mathrm{RD}$ to TD. While there is still a slight difference between the simulated and experimental results, it is insignificant in comparison with the experimental scatter expected in these experiments.

Finally we select the three R-values for tensile loading along $0^{\circ} / \mathrm{RD}$, $45^{\circ} / \mathrm{RD}$ and $90^{\circ} / \mathrm{RD}$ respectively (i.e., $\mathrm{R}_{0}, \mathrm{R}_{45}$ and $\mathrm{R}_{90}$ ) and use them to calculate the 4 Hill coefficients $F, G, H$ and $N$ for the Zn alloy using the following expressions:

$R_{0}=\frac{H}{G}, R_{45}=\frac{N}{F+G}-\frac{1}{2}, R_{90}=\frac{H}{F}$, and $G+H=1$

giving us the following values for the Hill coefficients for rolled $\mathrm{Zn}-\mathrm{Cu}$ Ti sheets of $0.65 \mathrm{~mm}$ thickness: $F=0.2805, G=0.885, H=0.115$ and $N=0.7692$.

These coefficients may be used to draw the Hill yield surface for the alloy in Fig. 13(b). The experimental points have also been shown in the same figure and the results appear to be coherent.

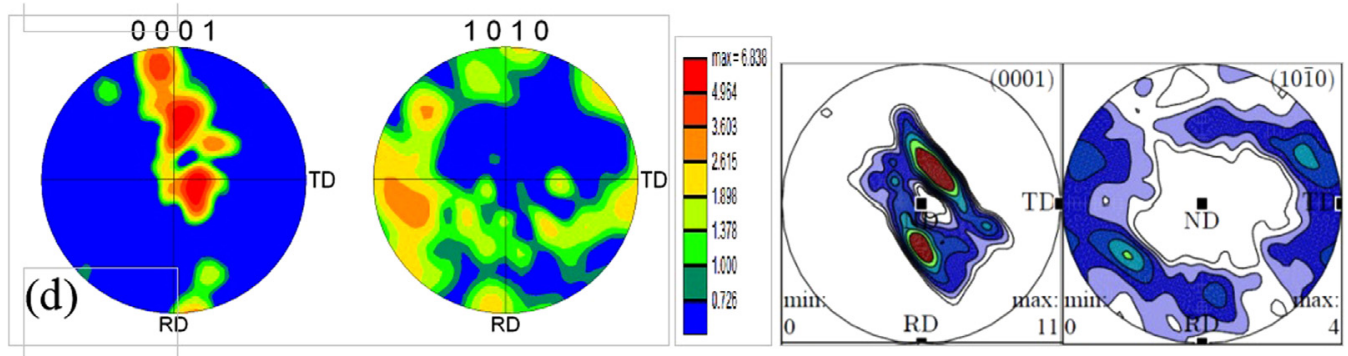

Fig. 11. Comparison of texture obtained by experiments (left) and simulations (right) for tensile loading along $45^{\circ} / \mathrm{RD}$ up to strain of $35 \%$. 


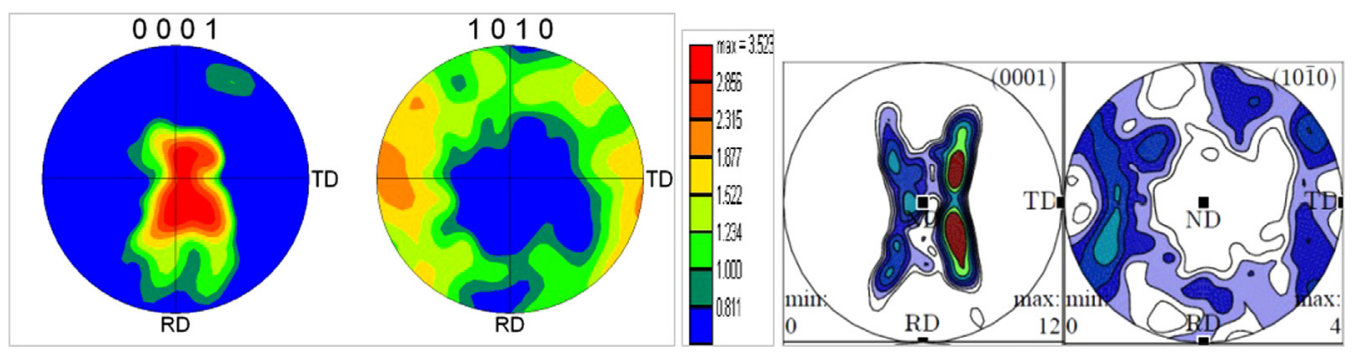

Fig. 12. Comparison of texture obtained by experiments (left) and simulations (right) for tensile loading along $90^{\circ} / \mathrm{RD}$ up to strain of $30 \%$.

\subsection{Comments}

We are able to get good agreement between simulation using the identified micro-scale parameters and experimental tensile testing along three different directions (namely, $0^{\circ} / \mathrm{RD}, 45^{\circ} / \mathrm{RD}$ and $90^{\circ} / \mathrm{RD}$ ). It goes without saying that the model is limited by the experiments used to fit its parameters. Several modes of deformation have a low influence in the type of experiment used, other than first order pyramidal and prismatic slip and possible twinning, and therefore an accurate fitting of the entire model is difficult.

Secondly, it is true that we have calculated a single R-value for a given direction throughout the loading process, and thus ended up with constant Hill coefficients for the alloy considered, while in practice, Rvalues (and therefore Hill coefficients) change slightly with increasing plastic strain. In addition, while we limited ourselves to the simulation of uniaxial tensile tests alone, the goal was to confirm the validity of the approach for predicting the mechanical response of the material. It goes without saying that this study could provide useful information for future work on equibiaxial tension tests or other more complicated loading cases and forming operations.

For accurate macroscopic simulation of the forming operations on zinc sheets, the required materials parameters must be identified using an experimental forming set up that permits the realization of the complex desired shapes and loading conditions. That said, there are several practical difficulties in achieving these experimental setups. Firstly, it is very time consuming to realize all the loading paths adopted in industry, and furthermore, it is often very difficult to realize certain loading paths such as thin sheet compression in the rolling direction.

For all such cases, the multi-scale modeling strategy provides a solution by allowing us to run corresponding virtual tests and also plot the yield surface of studied material. The model's capacity to handle different stress conditions is not beyond question. For example, shear

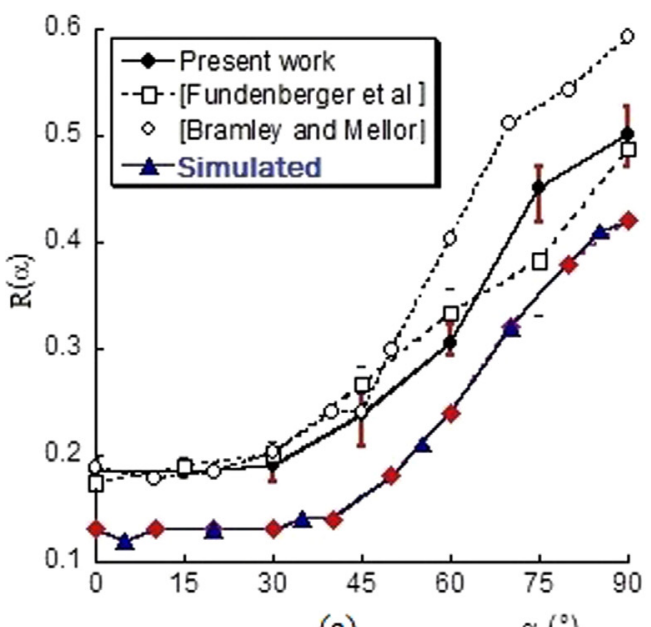

(a)

$\alpha\left({ }^{\circ}\right)$ experiments would not give satisfactory results if modeled using parameters identified by uniaxial tension alone, since the model would seemingly be inadequate to describe the mechanical response. This is likely due to two important reasons: firstly, the relatively low activity of twinning under uniaxial tension would provoke an inaccuracy in the parameter identification. Since only three deformation modes have been selected for investigation, this would seem prima facie insufficient for shear tests.

Nevertheless, the strength of the approach lies in its simplicity (needing little more than uniaxial tensile testing) ergo one can justify studying its validity over a wider range of applications to identify the material parameters (e.g. Lankford R-vaues and Hill coefficients). Furthermore, we observe that the simulated Lankford coefficients are in good agreement with the values reported in the literature.

\section{Conclusions}

Characterization of zinc alloys, while very important from an industrial standpoint, is rendered difficult by its highly anisotropic behavior that strongly depends on microstructural effects, i.e. loading orientation-dependent activation of different families of slip systems and subsequent texture evolution. In this work, the authors made a contribution to the development of a physics-based multi-scale model using crystal plasticity, to simplify the characterization and take these microstructural effects into account, instead of the traditional approach using a phenomenological anisotropy model in conjunction with a large number of experiments. The approach, based on the VPSC paradigm, involves a viscoplastic micromechanical model based on microstructure and deformation mechanism information obtained by Electron BackScattered Diffraction (EBSD), that is combined with a self-consistent homogenization scheme to develop the macroscale deformation under uniaxial tensile loading, that is then compared to the experimental results to identify the crystal parameters in an inverse analysis using the

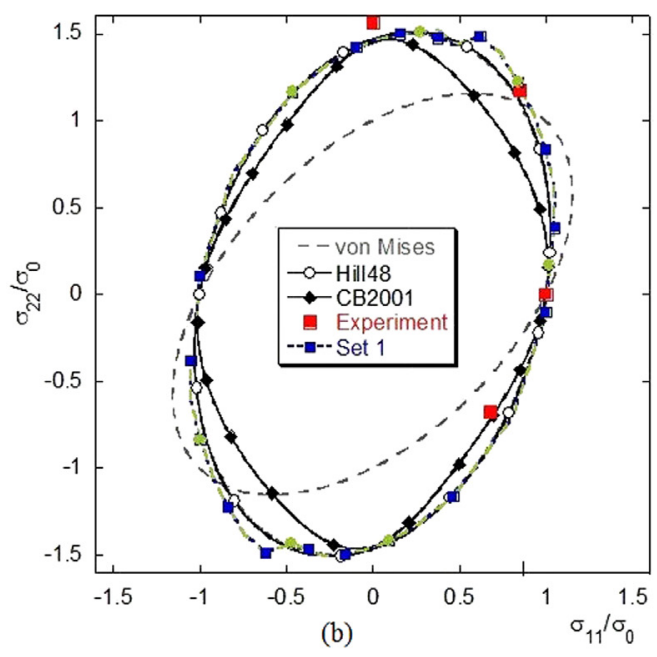

Fig. 13. (a) Comparison of Lankford coefficients (b) Yield surface - simulated and experimental. 
CMA-ES genetic algorithm. By considering 2 slip modes and 1 twinning mode, we are able to satisfactorily reproduce the macroscopic stressstrain curves under uniaxial tension. An obvious way to improve the method is by comparing the experimental and simulated pole figures for the final textures in addition to the macroscopic stress-strain curves.

\section{Acknowledgements}

The authors acknowledge Dr. Ricardo Lebensohn from Los Alamos National Laboratory for providing the VPSC code. We would also like to thank Hugues Marie, former student of Mechanical engineering at INSA Rennes and research intern at Laboratoire Roberval for his contribution to the work.

\section{References}

[1] R. Parisot, S. Forest, A.-F. Gourgues, A. Pineau, D. Mareuse, Modeling the mechanical behavior of a multicrystalline zinc coating on a hot-dip galvanized steel sheet, Comput. Mater. Sci. 19 (1-4) (2000) 189-204.

[2] L. Meng, P. Breitkopf, B. Raghavan, G. Mauvoisin, O. Bartier, X. Hernot, Identification of material properties using indentation test and shape manifold learning approach, Comput. Methods Appl. Mech. Eng. 297 (2015) 239-257.

[3] L. Meng, B. Raghavan, O. Bartier, X. Hernot, G. Mauvoisin, P. Breitkopf, An objective meta-modeling approach for indentation-based material characterization, Mech. Mater. 107 (2017) 31-44, http://dx.doi.org/10.1016/j.mechmat.2017.01. 011.

[4] C. Slunder, W. Boyd, Zinc: its corrosion resistance, Int. Lead. Zinc Res. Organ. (1983).

[5] C. van den Bos, H. Schnitger, X. Zhang, A. Hovestad, H. Terryn, J. de Wit, Influence of alloying elements on the corrosion resistance of rolled zinc sheet, Corros. Sci. 48 (6) (2006) 1483-1499, http://dx.doi.org/10.1016/j.corsci.2005.05.028 (URL $\langle$ http://www sciencedirect.com/science/article/pii/S0010938×05001629 〉).

[6] L.F.d. Senna, S.L. DÃaz, L.A. Sathler, Hardness analysis and morphological characterization of copper-zinc alloys produced in pyrophosphate-based electrolytes, Mater. Res. 8 (2005) 275-279, http://dx.doi.org/10.1590/S151614392005000300009.

[7] R.V. Mises, Mechanik der plastischen formanderung von kristallen, ZAMM - J. Appl. Math. Mech. / Z. Angew. Math. Mech. 8 (3) (1928) 161-185, http://dx.doi. org/10.1002/zamm.19280080302 (URL 〈http://dx.doi.org/10.1002/zamm. 19280080302〉)

[8] R.L. Bell, R.W. Cahn, The dynamics of twinning and the interrelation of slip and twinning in zinc crystals, Proc. R. Soc. 239 (1957) 494-521, http://dx.doi.org/10. 1098/rspa.1957.0058.

[9] J. Christian, S. Mahajan, Deformation twinning, Prog. Mater. Sci. 39 (1) (1995) 1-157, http://dx.doi.org/10.1016/0079-6425(94)00007-7.

[10] M. Philippe, F. Wagner, F. Mellab, C. Esling, J. Wegria, Modelling of texture evolution for materials of hexagonal symmetry-i. application to zinc alloys, Acta Metall. Et. Mater. 42 (1) (1994) 239-250, http://dx.doi.org/10.1016/09567151(94)90066-3.

[11] F. Zhang, G. Vincent, Y. Sha, L. Zuo, J. Fundenberger, C. Esling, Experimental and simulation textures in an asymmetrically rolled zinc alloy sheet, Scr. Mater. 50 (7) (2004) 1011-1015, http://dx.doi.org/10.1016/j.scriptamat.2003.12.031.

[12] S. Bouvier, A. Needleman, Effect of the number and orientation of active slip systems on plane strain single crystal indentation, Model. Simul. Mater. Sci. Eng. 14 (7) (2006) 1105 (URL 〈http://stacks.iop.org/0965-0393/14/i=7/a=001 〉).

[13] K. Yoshida, R. Brenner, B. Bacroix, S. Bouvier, Effect of regularization of schmid law on self-consistent estimates for rate-independent plasticity of polycrystals, Eur. J. Mech. - A/Solids 28 (5) (2009) 905-915, http://dx.doi.org/10.1016/j.euromechsol. 2009.05.001.

[14] M.E. Nixon, O. Cazacu, R.A. Lebensohn, Anisotropic response of high-purity $\alpha$-titanium: experimental characterization and constitutive modeling, Int. J. Plast. 26 (4) (2010) 516-532, http://dx.doi.org/10.1016/j.ijplas.2009.08.007.

[15] B. Panicaud, K.K. Saanouni, A.L. Baczmański, M. Francois, L. Cauvin, L. Le Joncour, Theoretical modelling of ductile damage in duplex stainless steels - comparison between two micro-mechanical elasto-plastic approaches, Comput. Mater. Sci. 50 (06) (2011) 1908-1916, http://dx.doi.org/10.1016/j.commatsci.2011.01.038.

[16] K. Yoshida, R. Brenner, B. Bacroix, S. Bouvier, Micromechanical modeling of the work-hardening behavior of single- and dual-phase steels under two-stage loading paths, Mater. Sci. Eng.: A 528 (3) (2011) 1037-1046, http://dx.doi.org/10.1016/j. msea.2010.10.078.

[17] S. Bouvier, N. Benmhenni, W. Tirry, F. Gregory, M. Nixon, O. Cazacu, L. Rabet, Hardening in relation with microstructure evolution of high purity $\alpha$-titanium de formed under monotonic and cyclic simple shear loadings at room temperature, Mater. Sci. Eng.: A 535 (2012) 12-21, http://dx.doi.org/10.1016/j.msea.2011.12. 033.

[18] N. Benmhenni, S. Bouvier, R. Brenner, T. Chauveau, B. Bacroix, Micromechanical modelling of monotonic loading of $\{\mathrm{CP}\} \alpha$-ti: Correlation between macroscopic and microscopic behaviour, Mater. Sci. Eng.: A 573 (2013) 222-233, http://dx.doi.org/ 10.1016/j.msea.2013.02.022.

[19] P. Gelineau, M. Stepień, S. Weigand, L. Cauvin, F. Bédoui, Elastic properties prediction of nano-clay reinforced polymer using multi-scale modeling based on a multi-scale characterization, Mech. Mater. 89 (2015) 12-22, http://dx.doi.org/10 1016/j.mechmat.2015.03.013.

[20] D. Chatziathanasiou, Y. Chemisky, F. Meraghni, G. Chatzigeorgiou, E. Patoor, Phase transformation of anisotropic shape memory alloys: theory and validation in superelasticity, Shape Mem. Superelasticity 1 (3) (2015) 359-374, http://dx.doi.org/ 10.1007/s40830-015-0027-y.

[21] H. Wang, B. Raeisinia, P. Wu, S. Agnew, C. Tomac, Evaluation of self-consistent polycrystal plasticity models for magnesium alloy az31b sheet, Int. J. Solids Struct. 47 (21) (2010) 2905-2917, http://dx.doi.org/10.1016/j.ijsolstr.2010.06.016.

[22] E. Herve, A. Zaoui, n-layered inclusion-based micromechanical modelling, Int. J. Eng. Sci. 31 (1) (1993) 1-10, http://dx.doi.org/10.1016/0020-7225(93)90059-4.

[23] R. Masson, M. Bornert, P. Suquet, A. Zaoui, An affine formulation for the prediction of the effective properties of nonlinear composites and polycrystals, J. Mech. Phys. Solids 48 (6) (2000) 1203-1227, http://dx.doi.org/10.1016/S0022-5096(99) 00071-X.

[24] R. Lebensohn, C. Tome, A self-consistent anisotropic approach for the simulation of plastic deformation and texture development of polycrystals: application to zirconium alloys, Acta Metall. Mater. 41 (9) (1993) 2611-2624.

[25] R. Lebensohn, C. Tome, A self-consistent viscoplastic model: prediction of rolling textures of anisotropic polycrystals, Mater. Sci. Eng.: A 175 (1) (1994) 71-82.

[26] R. Lebensohn, M. Gonzalez, C. Tome, A. Pochettino, Measurement and prediction of texture development during a rolling sequence of zircaloy-4 tubes, J. Nucl. Mater. 229 (1996) 57-64.

[27] R.A. Lebensohn, P.P. Castaneda, R. Brenner, O. Castelnau, Computational Methods for Microstructure-Property Relationships, Eds. S. Ghosh, D. Dimiduk, Springer, 2011, Ch. 11, pp. 393-441.

[28] N. Hansen, S.D. Müller, P. Koumoutsakos, Reducing the time complexity of the derandomized evolution strategy with covariance matrix adaptation (cma-es), Evol. Comput. 11 (1) (2003) 1-18, http://dx.doi.org/10.1162/106365603321828970.

[29] A. Bramley, P. Mellor, Plastic anisotropy of titanium and zinc sheets, Int. J. Mech Sci. 10 (3) (1968) 211-219, http://dx.doi.org/10.1016/0020-7403(68)90080-5.

[30] J. Fundenberger, M. Philippe, F. Wagner, C. Esling, Modelling and prediction of mechanical properties for materials with hexagonal symmetry (zinc, titanium and zirconium alloys), Acta Mater. 45 (10) (1997) 4041-4055, http://dx.doi.org/10. 1016/S1359-6454(97)00099-2.

[31] S. Morgan, Zinc and Its Alloys and Compounds, GKSS, Ellis Horwood Limited Publishers, 1985. URL 〈https://books, google.fr/books?Id = NJPYNwAACAAJ〉.

[32] C. Mathewson, A.Z. Institute, Zinc: the science and technology of the metal, its alloys and compounds, Hafner Pub. Co., 1970. URL 〈https://books.google.fr/ books? Id $=$ aVp8AAAAIAAJ $>$.

[33] C. Shuai, C. He, P. Feng, W. Guo, C. Gao, P. Wu, Y. Yang, S. Bin, Biodegradation mechanisms of selective laser-melted mg-xal-zn alloy: grain size and intermetallic phase, Virtual Phys. Prototyp. 13 (2) (2018) 59-69, http://dx.doi.org/10.1080/ 17452759.2017.1408918.

[34] T.H. Muster, W.D. Ganther, I.S. Cole, The influence of microstructure on surface phenomena: rolled zinc, Corros. Sci. 49 (4) (2007) 2037-2058.

[35] G. Pantazopoulos, A. Sampani, Analysis of a weld failure of a rolled zn-alloy strip - a case study, Engineering Failure Analysis 14 (4) (2007-06-01) 642(10).

[36] E. Edwards, J. Washburn, Mstrain hardening of latent slip systems in zinc crystals, Trans. AIME 200 (1954) 1239-1251.

[37] K.H. Adams, T.V. Jr., Impurity effects on basal dislocation in zinc single crystals, Trans. Metall. Soc. AIME 242 (1968) 132-139.

[38] K. Adams, R. Blish, T.V. Jr., Second-order pyramidal slip in zinc single crystals, Mater. Sci. Eng. 2 (1967) 201 - 207.

[39] M.E. Bosin, F.F. Lavrent'ev, V.N. Nikiforenko, Experimental and simulation textures in an asymmetrically skin-passed zinc galvanized sheet, Phys. Solid State 38 (1996) 1972-1975.

[40] P.B. Price, Nucleation and growth of twins in dislocation-free zinc crystals, Proc. R. Soc. Lond. Ser. A, Math. Phys. Sci. 260 (1960) 251-262.

[41] E. Stofel, D. Wood, Fracture of zinc single crystals, in: Fracture of solids, Metal. Soc. Conference 20 (1963) 521 - 539.

[42] K. Sztwiertnia, H. Mueller, F. Haessner, Interpretation of flow stress of textured zinc sheet, Mater. Sci. Technol. 1 (1985) 380-384.

[43] K. Wierzbanowski, Generalized computer program for texture simulation, Archs Hutn 27 (1982) 189-223.

[44] M. Diot, J. Fundenberger, M. Philippe, C. Esling, J. Wegria, Texture gradient in rolled zinc sheets, Scr. Mater. 39 (11) (1998) 1623-1630.

[45] L. Delannay, R.E. Logé, J.W. Signorelli, Y. Chastel, Prediction of the planar anisotropy of springback after bending of a textured zinc sheet, AIP Conference Proceedings 712 (1058)

[46] G. Boczkal, B. Mikulowski, Precipitation hardening of zn0.1 at.crystals deformed on

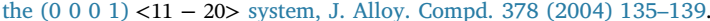

[47] G. Vincent, F. Zhang, J.J. Fundenberger, C. Esling, Experimental and simulation textures in an asymmetrically skin-passed zinc galvanized sheet, Scr. Mater. 53 (2005) 775-779.

[48] M. Philippe, F. Wagner, F. Mellab, C. Esling, J. Wegria, Modelling of texture evolution for materials of hexagonal symmetry i. application to zinc alloys, Acta Metall. Mater. 42 (1) (1994) 239-250, http://dx.doi.org/10.1016/0956-7151(94)90066-3.

[49] G. Sachs, Plasticity problems in metals, Trans. Faraday Soc. 24 (1928) 84-92, http://dx.doi.org/10.1039/TF9282400084.

[50] G.I. Taylor, Plastic strain in metals, J. Inst. Met. 62 (1938) 307-324.

[51] A. Molinari, G. Canova, S. Ahzi, A self consistent approach of the large deformation polycrystal viscoplasticity, Acta Metall. 35 (12) (1987) 2983-2994, http://dx.doi. org/10.1016/0001-6160(87)90297-5.

[52] E. Kröner, Berechnung der elastischen konstanten des vielkristalls aus den konstanten des einkristalls, Z. Phys. 151 (4) (1958) 504-518, http://dx.doi.org/10. 
1007/BF01337948.

[53] J.W. Hutchinson, Bounds and self-consistent estimates for creep of polycrystalline materials, Proc. R. Soc. Lond. A: Math., Phys. Eng. Sci. 348 (1652) (1976) 101-127, http://dx.doi.org/10.1098/rspa.1976.0027.

[54] R. Brenner, R. Masson, O. Castelnau, A. Zaoui, A quasi-elastic affine formulation for the homogenised behaviour of nonlinear viscoelastic polycrystals and composites, Eur. J. Mech. - A/Solids 21 (6) (2002) 943-960, http://dx.doi.org/10.1016/S09977538(02)01247-0.

[55] F. Meraghni, H. Nouri, N. Bourgeois, C. Czarnota, P. Lory, Parameters identification of fatigue damage model for short glass fiber reinforced polyamide (pa6-gf30) using digital image correlation, Procedia Engineering 10 (Supplement C) (2011) 2110-2116, In: Proceedings of the 11th International Conference on the Mechanical Behavior of Materials (ICM11). http://dx.doi.org/10.1016/j.proeng.2011.04.349.

[56] F. Meraghni, Y. Chemisky, B. Piotrowski, R. Echchorfi, N. Bourgeois, E. Patoor, Parameter identification of a thermodynamic model for superelastic shape memory alloys using analytical calculation of the sensitivity matrix, Eur. J. Mech. - A/Solids 45 (2014) 226-237, http://dx.doi.org/10.1016/j.euromechsol.2013.12.010 (Supplement C).
[57] Y. Chemisky, F. Meraghni, N. Bourgeois, S. Cornell, R. Echchorfi, E. Patoor, Analysis of the deformation paths and thermomechanical parameter identification of a shape memory alloy using digital image correlation over heterogeneous tests, Int. J. Mech. Sci. 96 (2015) 13-24, http://dx.doi.org/10.1016/j.ijmecsci.2015.03.007 (Supplement C).

[58] B. Nayroles, G. Touzot, P. Villon, Generalizing the finite element method: Diffuse approximation and diffuse elements, Comput. Mech. 10 (5) (1992) 307-318, http:// dx.doi.org/10.1007/BF00364252.

[59] J.C. Lagarias, J.A. Reeds, M.H. Wright, P.E. Wright, Convergence properties of the nelder-mead simplex method in low dimensions, SIAM J. Optim. 9 (1) (1998) 112-147, http://dx.doi.org/10.1137/S1052623496303470.

[60] P.G. Partridge, The crystallography and deformation modes of hexagonal closepacked metals, Metall. Rev. 12 (1) (1967) 169-194, http://dx.doi.org/10.1179/ mtlr.1967.12.1.169.

[61] D. Hou, T. Liu, D. Shi, H. Chen, H. Chen, Study of twinning behaviors of rolled az31 magnesium alloy by interrupted in situ compressive tests, Mater. Sci. Eng.: A 653 (2016) 108-114, http://dx.doi.org/10.1016/j.msea.2015.12.011. 